\title{
Twenty-five years of continuous sulphur dioxide emission reduction in Europe
}

\author{
V. Vestreng ${ }^{1}$, G. Myhre ${ }^{2}$, H. Fagerli ${ }^{1}$, S. Reis ${ }^{3}$, and L. Tarrasón ${ }^{1}$ \\ ${ }^{1}$ Air Pollution Section, Research Department, Norwegian Meteorological Institute, Oslo, Norway \\ ${ }^{2}$ Department of Geosciences, University of Oslo, Oslo, Norway \\ ${ }^{3}$ Atmospheric Sciences Section, Centre for Ecology \& Hydrology, Edinburgh, Scotland \\ Received: 9 February 2007 - Published in Atmos. Chem. Phys. Discuss.: 11 April 2007 \\ Revised: 4 July 2007 - Accepted: 4 July 2007 - Published: 12 July 2007
}

\begin{abstract}
During the last twenty-five years European emission data have been compiled and reported under the Cooperative Programme for Monitoring and Evaluation of the Longrange Transmission of Air Pollutants in Europe (EMEP) as part of the work under the UNECE Convention on Longrange Transboundary Air Pollution (LRTAP). This paper presents emission trends of $\mathrm{SO}_{2}$ reported to EMEP and validated within the programme for the period 1980-2004. These European anthropogenic sulphur emissions have been steadily decreasing over the last twenty-five years, amounting from about $55 \mathrm{Tg} \mathrm{SO}$ in 1980 to $15 \mathrm{Tg} \mathrm{SO}$ in 2004 . The uncertainty in sulphur emission estimates for individual countries and years are documented to range between $3 \%$ and $25 \%$. The relative contribution of European emissions to global anthropogenic sulphur emissions has been halved during this period. Based on annual emission reports from European countries, three emission reduction regimes have been identified. The period $1980-1989$ is characterized by low annual emission reductions (below 5\% reduction per year and $20 \%$ for the whole period) and is dominated by emission reductions in Western Europe. The period 1990-1999 is characterised by high annual emission reductions (up to $11 \%$ reduction per year and 54\% for the whole period), most pronounced in Central and Eastern Europe. The annual emission reductions in the period 2000-2004 are medium to low (below $6 \%$ reduction per year and $17 \%$ for the whole period) and reflect the unified Europe, with equally large reductions in both East and West. The sulphur emission reduction has been largest in the sector Combustion in energy and transformation industries, but substantial decreases are also seen in the Non-industrial combustion plants together with the sectors Industrial combustion and Industrial production
\end{abstract}

Correspondence to: V. Vestreng

(vigdis.vestreng@met.no) processes. The majority of European countries have reduced their emissions by more than $60 \%$ between 1990 and 2004, and one quarter have already achieved sulphur emission reductions higher than $80 \%$. At European level, the total sulphur target for 2010 set in the Gothenburg Protocol (16 Tg) has apparently already been met by 2004 . However, still half of the Parties to the Gothenburg Protocol have to reduce further their sulphur emissions in order to attain their individual country total emission targets for 2010. It is also noteworthy that, contrasting the Gothenburg Protocol requirements, a growing number of countries have recently been reporting increasing sulphur emissions, while others report only minor further decreases. The emission trends presented here are supported by different studies of air concentrations and depositions carried out within and outside the framework of the LRTAP Convention.

\section{Introduction}

Much attention has been given to the abatement of sulphur dioxide $\left(\mathrm{SO}_{2}\right)$ emissions since the 1970 s, when the transboundary character of air pollutants was first robustly established and documented (e.g. OECD, 1977; Eliassen and Saltbones, 1983; Menz and Seip, 2004; Grennfelt and Hov, 2005). In order to control these emissions, international cooperation was deemed indispensable and to that purpose, the United Nations Economic Commission for Europe (UNECE) Convention on Long-range Transboundary Air Pollution (LRTAP) was established in 1979. Today, the LRTAP Convention has fifty-one Parties, forty-seven of which are European. At present, there are three international Protocols from the LRTAP Convention in force to reduce sulphur dioxide emissions. While the first Protocol, the 1985 Sulphur

Published by Copernicus Publications on behalf of the European Geosciences Union. 
Protocol, adopted a flat rate approach (reduction of national annual sulphur emissions by at least $30 \%$ between 1980 and 1993), the two succeeding Protocols, the 1994 Sulphur Protocol and the 1999 Multi-effect Protocol (Gothenburg Protocol), are effects based (UNECE, 2004). This means that they aim at efficiently reducing sulphur emissions where environmental effects are most severe. In addition to the UN Protocols, several European Union (EU) Directives are regulating sulphur emissions, the most recent one being the $2001 \mathrm{Na}-$ tional Emission Ceilings (NEC) Directive, 2001/81/EC (EC, 2001), presently under revision. The NEC Directive establishes emission ceilings to be attained by 2010 for sulphur dioxide, nitrogen oxide, volatile organic compounds and ammonia for the $25 \mathrm{EU}$ Member States. Targets for the Member States that joined the EU in 2003 are specified in the Treaty of Accession (EU, 2003). In general, the sulphur emission targets for 2010 in the NEC Directive are more ambitious than those in the Gothenburg Protocol.

The main anthropogenic source of sulphur dioxide emissions is the sulphur content of fossil fuels released by combustion. In addition, some sulphur arises from petroleum refining, the smelting of sulphidic ores in the production of heavy metals, in the production of sulphuric acid, paper and sulphur. Natural fluxes of sulphur originate from volcanoes, and biological and photochemical production in the oceans of volatile sulphur gases, notably dimethyl sulphide (DMS). Comparably small amounts of sulphur are also emitted from forest fires, soils and vegetation, sulphur springs and sea salt (Simpson et al., 1999).

Sulphur emissions influence the level of acidification of soils and freshwater ecosystems (e.g. Stoddard et al., 1999; Schöpp et al., 2003), climate change (e.g. Haywood and Boucher, 2000; Ramanathan et al., 2001) and have impacts on human health (e.g. WHO, 2003, 2005, 2006). The acidification situation has been serious in large parts of northern Europe in the 1970s, mainly in the Fenno-Scandia region also due to slow weathering of soil and bedrock. Significant exceedances of critical loads were observed over large parts of central Europe, southern parts of Scandinavia and NorthWestern Europe (Lövblad et al., 2004). Emission and successive deposition of sulphur have caused material, soil and forest damage (e.g. Nellemann and Goul Thomsen, 2001; Akselsson et al., 2004) and surface water acidification. Decreased $\mathrm{pH}$ and accompanying increase of aluminium compounds is fatal to fresh water fish, and in many lakes e.g. in the southern part of Scandinavia the whole fish population was completely exterminated by 1986 (e.g. Henriksen et al., 1989; Rohde et al., 1995; Yakovlev, 2001; Gunn and Sandøy, 2003; Skjelkvåle et al., 2003). A thorough review and assessment of air pollution trends and their effects was carried out with the occasion of the Convention's 25 years anniversary in 2004 (Sliggers and Kakebeeke, 2004), complemented by studies from the EMEP programme (Lövblad et al., 2004) and by the Working Group of Effects under the LRTAP Convention (WGE, 2004) .
While the attention traditionally was directed towards the "acid rain" environmental problem of sulphur compounds described above, the emphasis today tends to be more on the climate and human health impacts of the particulate phase of sulphur. The most severe effects in terms of overall health burden of air pollution are associated with the long-term exposure to particulate matter. A significant reduction in life expectancy of the average population by a year or more has been estimated if present levels are to continue (WHO, 2006). In this context, the latest update of the World Health Organization (WHO) Air Quality Guidelines (WHO, 2005) reflects the need to provide a larger degree of protection against $\mathrm{SO}_{2}$ emissions than preceding documents (WHO, 2000). Hence the limit values of $20 \mu \mathrm{gm}^{-3}$ for $24 \mathrm{~h}$ average exposure and $500 \mu \mathrm{gm}^{-3}$ for a 10 -min average are much more stringent than in the 2000 revision of the Guidelines where the limit was $125 \mu \mathrm{gm}^{-3}$ as a $24 \mathrm{~h}$ average (WHO, 2005). However, if $\mathrm{SO}_{2}$ emissions should be reduced to levels which are certain to be associated with no effects, the levels would have yet to be much lower than in the current guidelines (WHO, 2005, and references therein).

$\mathrm{SO}_{2}$ is an aerosol precursor and can be converted to sulphate aerosols. Both sulphur dioxide and sulphate have life times of less than a week, hence the influence of sulphur releases is mainly of regional character. Sulphate aerosols are shown to have a significant direct aerosol effect (Haywood and Boucher, 2000; Schulz et al., 2006) and are an important contributor to indirect aerosol effects (Haywood and Boucher, 2000; Ramanathan et al., 2001; Lohmann and Feichter, 2005). The direct and indirect aerosol effects due to sulphate lead to a negative radiative forcing and thus a cooling effect on climate. Myhre et al. (2004) showed that emission changes of $\mathrm{SO}_{2}$ between 1985 and 1996 impact the geographical distribution of the radiative forcing of the direct aerosol effect substantially. Global anthropogenic sulphur emissions have been shown to increase rather steadily up to about 1980, but with a more uncertain trend after that (Boucher and Pham, 2002; Smith et al., 2004; Stern, 2006). The global trend is uncertain over the last decades since it consists of large reduction over North America and Europe and a large increase over Asia. Several authors have studied the possible impact on sulphur deposition due to changes in regional climate (e.g. Mayerhofer et al., 2002; Langner et al., 2005; Sanderson et al., 2006). Changes in weather pattern, temperature and precipitation has been found to both increase and to decrease acidification, imposing changes of about $\pm 5 \%$ in sulphur deposition patterns depending on location.

In order to trace the progress in controlling transboundary air pollution and its related effects, the founding Protocol under the LRTAP Convention in 1979 agreed on the exchange of information by countries on emission data and on transboundary fluxes. The compilation of both emission data and information on transboundary fluxes has been carried out under the Cooperative Programme for Monitoring 
and Evaluation of the Long-range Transmission of Air Pollutants in Europe, also named the EMEP programme. Every year since the start of the programme, EMEP has published the officially submitted information on emissions and transboundary fluxes, in recent years as well online in the EMEP emission database (http://www.emep.int and http://webdab. emep.int).

This paper presents the twenty five year trends for sulphur emissions in the EMEP area as estimated within the EMEP programme and documents the sulphur trend by country and sector in time and space. Special focus is given to the post 1990 development and the present 2004 emissions are compared with the ceilings for 2010 in the LRTAP 1999 Multi-effect Protocol (Gothenburg Protocol). Emission targets in the NEC Directive are not included, as the emission reporting requirements, hence the national total emissions reported, differs on several points between the LRTAP Convention and the NEC Directive. In addition, final NEC emission data is only complete for the EU-15 total emissions for four years (20012004) (http://reports.eea.europa.eu/technical_report_2006_8/ en/technical_report_2006_8.pdf); hence analysis of long-term trends, which is the focus in this paper, cannot be undertaken. Emissions included here are only anthropogenic national emissions. Natural sources of sulphur are not considered here and neither are sulphur emissions from international shipping and international aviation. Although emissions from international air and sea transport may prove to contribute significantly to European air pollution assessments, these are beyond the scope of the present paper. This is the first time that the 25 years of sulphur dioxides emissions reported under EMEP are presented and analysed in peer reviewed literature. In this paper, we first discuss quality aspects of EMEP emissions data and how we work towards a complete validation of the EMEP inventory through annual review processes and by top-down assessments. The emission improvement program under EMEP has increased the transparency and confidence in official submission and is a main reason to support for the first time the publication of the EMEP trends. At the end of the paper, we discuss also the uncertainty ranges in the EMEP inventory and how the EMEP trend compares with other independent estimates and the European emission contribution to global anthropogenic sulphur inventories.

\section{Emission sources and methodology}

The main source of emission data used under the LRTAP Convention is national official emission reports (http: //webdab.emep.int/, 6th version). Every year, emission data per sector from Parties to the LRTAP Convention is compiled at national level and are reported through the EMEP programme. The emission data are reported in the Nomenclature For Reporting (NFR) source categories. There are 102
NFR categories in the reporting templates (http://www.emep. int/emis2007/reportinginstructions.html), including both detailed categories (e.g. Residential plants, Passenger cars and Iron and Steel, in addition to Public Electricity and Heat Production) as well as the associated aggregated levels (e.g. Residential, Road Transport and Manufacturing Industries and Construction) to facilitate reporting under the Convention also for Parties with less resources available for emission estimation and reporting. Reporting according to NFR mostly applies for the 1990 and onwards emission data. The 1980 s are still dominated by emission data reported in the eleven SNAP (Selected Nomenclature for Air Pollutants) source sectors as defined in the EMEP/CORINAIR Guidebook (http://reports.eea.europa.eu/ EMEPCORINAIR4/en), i.e. less detailed information is available for this time period. The national inventories are based on national statistics and country specific, technology dependant emission factors. National experts are requested to estimate their national emissions according to the EMEP/CORINAIR Emission Inventory Guidebook. The Guidebook offers a three Tier approach for emission estimation (http://www.ipcc-nggip.iges.or.jp/public/2006gl for a definition of Tiers). By moving from a lower to a higher Tier, more specific emission factors, more detailed activity information, specific abatement strategies and other relevant technical information is required. The Tier approach allows all Parties to apply the Guidebook for their emission estimation irrespectively of resources and or detail of information available for emission estimation, as emissions can be estimated on different levels of complexity. If country specific methodologies are applied, these should be documented separately. This documentation is rather scars for the 1980s, as it is only the past few years that the requirements for national emission data have become more transparent and guidelines on emission reporting, requesting also Informative Inventory Reports (IIRs), have become available (UNECE, 2003). In addition, new routines and standards for validating emission data have recently been adopted (UNECE, 2005).

Whenever there is a lack of reported data, or the officially reported data fails to pass the quality control established in the annual review (UNECE, 2005) described in more detail below, the sector emissions are either gap-filled or replaced by independent estimates and by linear interpolation and extrapolation. The main source of information for the independent estimates is emission data from the RAINS (Regional Air Pollution INformation and Simulation) model (Amann, 2005a, b). RAINS data is currently the preferred choice, since the datasets have been thoroughly reviewed with national experts through the Clean Air For Europe (CAFÉ) programme and proved to be largely consistent and comparable with officially reported data. The methodology used to derive the RAINS emission estimates is well documented (http://www.iiasa.ac.at/rains/cafe.html). If no data has been submitted under the LRTAP Convention, and RAINS data is not available, EDGAR emission 
data (http://www.mnp.nl/edgar/) has been used instead, as these inventories to our knowledge are the only readily available emission inventories which covers several years of $\mathrm{SO}_{2}$ sector data information for all European countries. In some cases, when sector data for a particular year and a particular country is missing, but data for other years are available from the country, interpolation of the values is used instead. Extrapolation of country trends is seldom required, and mostly used for the latest year when a Party has failed to submit data in time.

For the scope of this study, the emission sector data is presented according to SNAP source sectors as defined in the EMEP/CORINAIR Guidebook (http://reports.eea.europa.eu/ EMEPCORINAIR4/en). Sulphur emission trends prior to 1980 are taken according to Mylona $(1996,1997)$. The source of projected emissions data for 2010 is the emissions ceilings as stated in the Gothenburg Protocol (UNECE, 2004) supplied with RAINS scenario data (Amann, 2005a, b).

\section{Validation of the EMEP emission data}

\subsection{The review process}

For the last three years, new routines to evaluate and improve the quality of emission data officially reported under the Convention on LRTAP and the National Ceilings Directive (NEC) have been established under the EMEP programme in collaboration with the European Environmental Agency (EEA) and its European Topic Centre on Air Quality and Climate Change (ETC-ACC). The review is based on the key parameters Transparency, Consistency, Comparability, Completeness and Accuracy as defined in the Emission Reporting Guidelines from UNECE (2003).

The estimation and validation of European emission data is first facilitated through the continuous development of the EMEP/CORINAIR Guidebook. The Emission Inventory Guidebook (http://reports.eea.europa.eu/ EMEPCORINAIR4/en) assists the national experts in their emission estimation work and is intended to reflect the best available knowledge on methodology and choice of emission factors for all components and sectors required for reporting. Whenever updates of the Guidebook become available that may affect the estimation of a certain pollutant, the Parties are requested to recalculate the whole emission time series in order to secure methodologically consistent emission time series. The use of a common methodological framework also aims to assure comparability between national emission inventories, and adds to the transparency of the inventories.

The review of the national emission estimates is presently organised according to recent routines established in UNECE (2005). The review of emission data consists of three stages;

1. Stage I checks the timeliness and format of submissions;
2. Stage II evaluates key sources (IPCC, 2000) and establishes the completeness, consistency, comparability and transparency of reported data, and

3. Stage III involves an in-depth review by individual countries which aims at establishing the actual accuracy of the emission estimates.

Annual Stage I and II emission data reviews are performed by a review team of experts. These reviews have been performed by EMEP since 2004 in collaboration with ETCACC and the UNECE secretariat, covering both data reported under the NEC Directive and under the Convention on LRTAP. Each Member State and Party is provided with a country specific review report three months after the data submission, summarizing conclusions from the review and the bilateral discussions with individual country emission experts necessary for clarification of certain aspects of the emission data. Countries are encouraged to give explanations for or correct data within the next reporting round. Meanwhile, if an explanation is not found, a replacement of country data by independent estimates is undertaken. As mentioned also in Sect. 2, replacements might simply consist of linear interpolation between two adjacent years. Whenever outliers are identified several places in the inventory, it is necessary to replace the whole time series by independent estimates, as the latter rarely will be fully consistent with the emission data provided by the country itself. General conclusions from the review are subsequently documented in an annual joint EMEP/EEA review report (e.g. Vestreng et al., 2006a). In addition, well organized reporting routines have proven to be crucial in the work of inventory improvement under EMEP. Thus, upfront the annual submission of data, reporting instructions detailing the requirements as laid down in the Emission Reporting Guidelines (UNECE, 2003) together with template files for reporting are made available online. Further to that, an online QA/QC tool, REPDAB (Vestreng, 2003), checking the completeness and consistency of reported emission data has been developed and made available to countries for quality control of data before submission.

Despite the short time since the initiation of the new emission data review routines, there has been considerable improvement in the quality of the reported emission estimates. The results from Stage I reviews indicate that from 2004 to 2006 the number of reports submitted within deadline has increased by $50 \%$, thus improving the timeliness of the inventory. It is also an achievement that emission data are now reported to EMEP in the agreed file structure and according to the agreed Nomenclature For Reporting (NFR) formats. Aggregated sectors are generally consistent with the more detailed categories reported. This is thought to be mainly due to the set up of the reporting routines, the availability and use of REPDAB and the review team's increased focus on the importance of consistency for the review process. The improvements made under the Stage I review facilitate considerably the review tasks under Stage II below. 
The transparency and the availability of additional information concerning the compilation of the national emission inventories has dramatically increased thanks to the active involvement of national experts in the review. The number of Informative Inventory Reports (IIR) with detailed information on the methodologies used to compile emissions and justification of changes with respect to the EMEP/CORINAIR Guidebook has increased threefold in the last three years. Also the number of bilateral consultations with national experts and the number of replies to the country specific review reports has considerably increased. This means that the transparency of emission data as defined in the Emission Reporting Guidelines (UNECE, 2003), has greatly improved over a relatively short time period.

Differences amongst countries due to differences in emission estimation methodologies and reporting guidelines are assessed through five comparability tests in the Stage II review. The tests include recalculations, inventory comparisons (NEC or United Nations Framework Convention on Climate Change (UNFCCC) reported data versus LRTAP data comparisons), implied emission factor (IEF) and cross pollutant checks, as well as the basis for transport emission calculations (fuel used versus fuel sold). Results which fall outside the empirical ranges of averages are identified as outliers by the review team of experts, thus possibly an error, which could however well be explained by national and source-specific circumstances not familiar to the review team. The review team seeks to find explanations for defined outliers in the submitted IIRs, based on knowledge within the expert review team and through country replies to its review reports. The conclusion so far is that most countries follow the methodologies in the EMEP/CORINAIR Guidebook although different Tiers are used in different countries, implying that the quality and comparability of the inventories are not fully homogenous throughout the whole EMEP area.

The consistency and completeness of reported time series of emission data per sector is crucial in trend studies of air pollution. As stated before, Parties are encouraged to submit complete inventories and recalculate the whole time series of emissions whenever new information becomes available. However, sometimes only the latest years or data back to 1990 are recalculated by applying best available methodologies and emission factors, while the remaining part of the time series may consist of data reported according to SNAP source categories. The fact that an inventory consists of reported data in different formats does not necessarily mean that the data are not consistent according to the emission data review. The review team analyses the consistency of all the reports by testing the behaviour of the time series for each particular sector in each individual country. Outliers are defined as dips and jumps in the time series depending on sector and pollutant and flagged for potential replacements necessary to be performed in order to guarantee consistency over time.
For $\mathrm{SO}_{2}$ about $30 \%$ of the reported sector data for each year has to be replaced by independent estimates and about $10 \%$ of the required emissions are not submitted. This implies that officially reported and accepted sector emissions cover only $60 \%$ of the total sulphur trend time series from 1990 until present (Vestreng et al., 2006b). Completeness in the 1980s has not yet been quantified, but is known to be lower (e.g. Vestreng et al., 2005). The completeness of the time series varies also spatially across Europe, with a larger lack of officially reported data in Eastern Europe, Central Asia and Caucasus countries. This is indicated in Table 1 where countries are presented in four groups ranging on the level of completeness of the reported and reviewed times series of $\mathrm{SO}_{2}$ emission data. The first group is highlighted in grey and corresponds to the nineteen countries that have a complete and consistent official report of sulphur emissions for all years since 1980. The second group of countries represents the countries where data has been reported for most of the sectors and years but with gaps that needed to be filled. These are a total of thirteen countries and are indicated with bold italics. The third group of countries have not reported any or only fragmentary official estimates and for these RAINS estimates, interpolation or extrapolation have been used instead. These are Albania, Bosnia and Herzegovina, Luxembourg, the Russian Federation, Serbia and Montenegro, The Former Yugoslav Republic (TFYR) of Macedonia and Turkey, a total of seven countries indicated in Table 1 with stars behind the country names. The last group of countries are those that have not reported any or very little official estimates and for which RAINS data estimates are not available, so that EDGAR data have been used instead. These are: Armenia, Azerbaijan, Georgia, Iceland and Kazakhstan, a total of five countries indicated in Table 1 in normal font.

It is worth noting that replacements are never used for compliance checking performed under the LRTAP Convention, but merely to assist in atmospheric transport calculations and impact assessments. Feedback from the national experts themselves and from the review team of experts indicate that the emission data improve through the review process, but so far it has been difficult to directly quantify the improvements, mainly because the Emission Reporting Guidelines (UNECE, 2003) does not give clear guidance regarding what criteria to review against, and in addition, some of the review tests have been altered or added from one year to the next. The review is done for each reported pollutant, and for some pollutants like particulate matter and pesticides, the EMEP/CORINAIR Guidebook does not provide sufficient information. Conclusions on the review of reported persistent organic pollutants can be found for example in Breivik et al. (2006).

Additionally to the sector totals, spatially distributed emissions are necessary for modelling the dispersion of sulphur pollution. The completeness of official reports of spatially distributed sector data is lower than for the sector totals. Gridded sector data is requested in five-yearly intervals from 
Table 1. Sulphur trends per European country 1980-2004 (Unit: Gg SO 2 ). Countries highlighted in - Grey: Officially reported data. Bold italics: Reported data completed by independent estimates. Stars: RAINS data, interpolation and extrapolation. Normal: EDGAR data, interpolation and extrapolation

\begin{tabular}{|c|c|c|c|c|c|c|}
\hline & 1980 & 1985 & 1990 & 1995 & 2000 & 2004 \\
\hline Albania* & 72 & 73 & 74 & 14 & 32 & 32 \\
\hline Armenia & 141 & 100 & 86 & 15 & 11 & 8 \\
\hline Austria & 344 & 179 & 74 & 47 & 32 & 29 \\
\hline Azerbaijan & 603 & 543 & 615 & 262 & 162 & 130 \\
\hline Belarus & 740 & 690 & 888 & 344 & 162 & 97 \\
\hline Belgium & 828 & 400 & 361 & 262 & 171 & 154 \\
\hline Bosnia and Herzegovina* & 482 & 483 & 484 & 360 & 420 & 427 \\
\hline Bulgaria & 2050 & 2314 & 2007 & 1477 & 918 & 929 \\
\hline Croatia & 150 & 164 & 178 & 70 & 60 & 85 \\
\hline Cyprus & 28 & 35 & 46 & 41 & 51 & 45 \\
\hline Czech Republic & 2257 & 2277 & 1876 & 1090 & 264 & 227 \\
\hline Denmark & 450 & 333 & 176 & 133 & 27 & 23 \\
\hline Estonia & 287 & 254 & 274 & 117 & 96 & 90 \\
\hline Finland & 584 & 382 & 259 & 95 & 74 & 83 \\
\hline France & 3216 & 1496 & 1333 & 968 & 613 & 484 \\
\hline Georgia & 230 & 273 & 43 & 6 & 7 & 5 \\
\hline Germany & 7514 & 7732 & 5289 & 1708 & 630 & 559 \\
\hline Greece & 400 & 500 & 487 & 536 & 493 & 537 \\
\hline Hungary & 1633 & 1404 & 1011 & 705 & 486 & 240 \\
\hline Iceland & 18 & 18 & 9 & 9 & 9 & 9 \\
\hline Ireland & 222 & 140 & 186 & 161 & 131 & 71 \\
\hline Italy & 3437 & 2045 & 1795 & 1320 & 755 & 496 \\
\hline Kazakhstan & 639 & 575 & 651 & 528 & 506 & 425 \\
\hline Latvia & 96 & 97 & 97 & 47 & 10 & 4 \\
\hline Lithuania & 311 & 304 & 263 & 92 & 43 & 40 \\
\hline Luxembourg* & 26 & 26 & 26 & 7 & 4 & 4 \\
\hline Malta & 29 & 29 & 29 & 33 & 26 & 17 \\
\hline Netherlands & 490 & 258 & 189 & 127 & 72 & 66 \\
\hline Norway & 136 & 91 & 53 & 34 & 27 & 25 \\
\hline Poland & 4100 & 4300 & 3278 & 2381 & 1507 & 1286 \\
\hline Portugal & 266 & 198 & 317 & 332 & 306 & 203 \\
\hline Republic of Moldova & 308 & 282 & 175 & 94 & 13 & 15 \\
\hline Romania & 1055 & 1255 & 1310 & 882 & 727 & 685 \\
\hline Russian Federation* & 7323 & 6350 & 6113 & 3101 & 2263 & 1858 \\
\hline Serbia and Montenegro* & 406 & 478 & 593 & 428 & 396 & 341 \\
\hline Slovakia & 780 & 613 & 542 & 239 & 127 & 97 \\
\hline Slovenia & 234 & 241 & 198 & 127 & 99 & 55 \\
\hline Spain & 3024 & 2542 & 2103 & 1809 & 1479 & 1360 \\
\hline Sweden & 491 & 266 & 117 & 79 & 52 & 47 \\
\hline Switzerland & 116 & 76 & 42 & 28 & 19 & 17 \\
\hline TFYR of Macedonia* & 107 & 109 & 110 & 93 & 90 & 87 \\
\hline Turkey* & 1030 & 1345 & 1519 & 1397 & 2122 & 1792 \\
\hline Ukraine & 3849 & 3463 & 3921 & 2342 & 1599 & 1145 \\
\hline United Kingdom & 4838 & 3714 & 3699 & 2343 & 1173 & 833 \\
\hline Grand Total & 55340 & 48448 & 42896 & 26282 & 18263 & 15162 \\
\hline
\end{tabular}

1990 onwards, but only twelve Parties to the LRTAP Convention have reported gridded sector data of any vintage in the $50 \times 50 \mathrm{~km}^{2}$ EMEP grid by 2006 (http://www.emep.int/grid/).
These countries represent $24 \%$ of the emissions and $25 \%$ of the area covered by the Parties listed in Table 1. EMEP is thus required to account for the spatial distribution of 
emissions for a large part of Europe by applying its own methods. The methodology for allocating $\mathrm{SO}_{2}$ emissions is mainly dependent on the distribution of large point sources, but additional information is also necessary on vertical and temporal variation of emissions (Tarrasón et al., 2004). Review of gridded sector data is also performed under EMEP, but is at present not formalized to the same extent as for the emission totals and is out of the scope for this study.

\subsection{Validation of European $\mathrm{SO}_{2}$ emission trends using} measurements and modelling

In addition to the review of emission data mentioned above, top-down assessments that use both measurements and modelling of air concentrations and depositions are of significant importance to increase the confidence in emission data. It is well known that the sulphur components can be transported over long distances, thus the validation of emission trends cannot be judged by comparing measurements in a region with local emissions. Moreover, the processes that determine the distribution between the different sulphur components (e.g. sulphur dioxide, sulphate and the amount of sulphur deposited dry and wet) may change depending on the chemical composition of the atmosphere as well as meteorological conditions. For instance, the oxidation of sulphur dioxide to sulphate depends on the availability of oxidants, and in the late 1970 s to early 1980 s when $\mathrm{SO}_{2}$ emissions peaked, the amount of oxidants was a limitation for the conversion of $\mathrm{SO}_{2}$ to sulphate, especially in winter (Fagerli et al., 2003; Roelofs et al., 1998). At present, larger proportions of $\mathrm{SO}_{2}$ are converted to sulphate. This has led to a smaller decrease in sulphate concentrations than in $\mathrm{SO}_{2}$ emissions. Moreover, whilst $\mathrm{SO}_{2}$ emissions have decreased dramatically, ammonia emissions have remained at the same level (Vestreng et al., 2005). As a consequence the dry deposition of $\mathrm{SO}_{2}$ has become more efficient over the years, as the surface acidity to a large extent governs the resistance to dry deposition (Fowler et al., 2001). Finally, year-to-year variations both in air concentrations and wet deposition are large, e.g. of the order of $20 \%$ for sulphate (van Loon et al., 2005), and thus long time series are needed in order to detect trends in observations.

In order to use measurements to validate the emission trends, it is important to know in what direction and to what extent the trends derived from measurements could be expected to deviate from the emission trends. Furthermore, model simulations may indirectly be used to validate emission trends by comparing the model output to measurements, providing that they incorporate the important processes. $\mathrm{SO}_{2}$ and sulphate background concentrations have been monitored in Europe at several sites since around 1980, for instance through the EMEP Programme. Lövblad et al. (2004) assessed the trends in EMEP emissions and measured atmospheric concentrations and deposition of sulphur compounds in Europe from the end of the 1970s until 2000. For $\mathrm{SO}_{2}$, they found national reductions in $\mathrm{SO}_{2}$ emissions and average reductions in $\mathrm{SO}_{2}$ measurement concentrations at national sites to correspond well. Both measurements and emissions changed around 90\% for countries like Germany, United Kingdom, Sweden, Austria, Finland and Denmark. For Czech Republic, Italy, Latvia, Lithuania and Switzerland differences between the reductions in the national EMEP $\mathrm{SO}_{2}$ emission inventories and the change in average $\mathrm{SO}_{2}$ concentrations was in the order of 5\%. A somewhat larger difference was found in Belarus and Slovakia (emission reductions of $80-85 \%$, average $\mathrm{SO}_{2}$ concentration reductions of $60-65 \%$ ), possibly due to the location of the sites. Measurement sites situated at high altitudes, near large sources in neighbouring countries or downwind of large indigenous sources do not necessarily show the same trend as the national emission. In general, however, agreement between national emission reductions and concentrations at sites in a country for the primary component $\mathrm{SO}_{2}$ are better than for the secondary component, sulphate, that are transported over longer distances. For sulphate, the decrease was found to be less than for $\mathrm{SO}_{2}$ (typically 50-70\%), consistent with the higher conversion rate to sulphate during this period as discussed above. The same pattern was found for oxidized sulphur in precipitation, probably because sulphate particles are the main contributor to oxidized sulphur in precipitation. In conclusion, the trend in the measurement data was found to support the reported trend in emissions.

Model simulations can also be used to validate emission changes indirectly through comparison with measurements, however, only a few studies aiming at comparing long term trends in measurements with modelled trends have been performed. Berglen et al. (2006) modelled 1985, 1995 and 2000 using the EMEP and Smith et al. (2004) inventories, together with the combined GEIA (http://geiacenter.org)/EDGAR (http://www.mnp.nl/edgar)/Aerocom (Dentener et al., 2006) dataset. They were able to reproduce the sulphate trends to a large extent, although the model showed a slightly smaller decrease (52\%) than the observations (59\%) for the 1985 to 2000 period using the EMEP inventory. Sulphur dioxide was increasingly overestimated over the years from $122 \%$ (modelled concentrations are in average more than twice as large as observed) in 1985 to $349 \%$ in 2000 . Although the modelled and measured decreases for sulphate 1985-2000 correspond within a few percent, indicating that the trend in the emission data is reasonable, it is difficult to conclude more specifically on the quantity of the emission trend, as the trends in the primary component $\mathrm{SO}_{2}$ (which are closely related to the emission changes) are not very well reproduced in their model simulations.

Evaluation of sulphur trends in air and precipitation using the EMEP Unified model have also been carried out using the EMEP inventory (Fagerli et al., 2003). In this study, 9 different years were calculated (1980, 1985, 1990, 1995-2000), taking into account also the annual meteorological variability. The sulphate trends were well reproduced, with a deviation between model results and EMEP measurements (on 


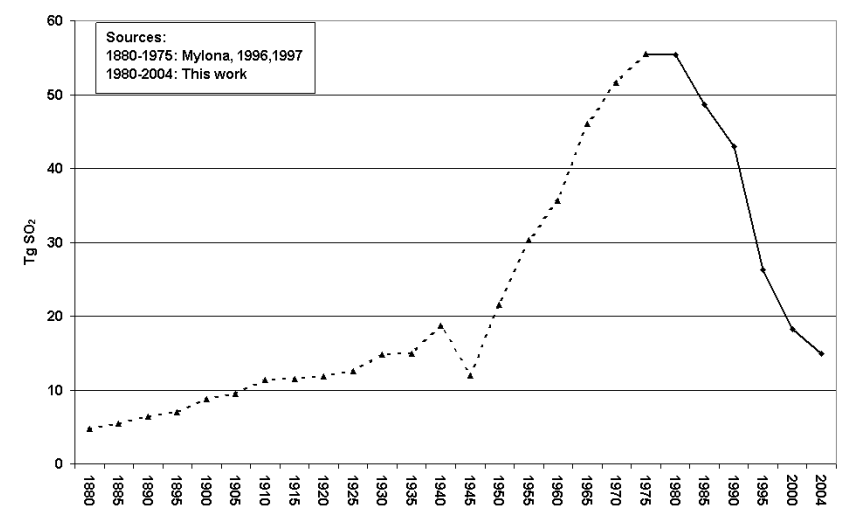

Fig. 1. Historical development of sulphur dioxide emissions in Europe (Unit: $\mathrm{Tg} \mathrm{SO}_{2}$ ).

average) between $-10 \%$ and $6 \%$ for the different years. Similar to Berglen et al. (2006), the decrease in $\mathrm{SO}_{2}$ concentrations between 1980 and 2000 was too low compared to the decrease in observations. Whilst modelled $\mathrm{SO}_{2}$ concentrations in 1980 were in good agreement with the observations (on average overestimated by $4 \%$ ), the model simulations overestimated $\mathrm{SO}_{2}$ by $39 \%$ in 2000. In the EMEP Unified model, a parameterisation of the so-called co-deposition of $\mathrm{NH}_{3}$ and $\mathrm{SO}_{2}$ is implemented in the dry deposition module (Simpson et al., 2003). If this effect is not taken into account, the overestimation of $\mathrm{SO}_{2}$ around 2000 is even larger (around 80\%), whilst it has little effect around 1980 when $\mathrm{SO}_{2}$ emissions peaked (H. Fagerli, personal communication, 2007). Thus, a part of the increasing overestimation of $\mathrm{SO}_{2}$ as calculated by Berglen et al. (2006) can be explained by the rather simple dry deposition scheme in their model. It is not clear why the EMEP model still overestimate $\mathrm{SO}_{2}$ for recent years. However, the major part of the reduction in the $\mathrm{SO}_{2}$ concentrations are captured by the model simulations, hence the trend in the EMEP $\mathrm{SO}_{2}$ emission inventory does correspond to the observed decreases in $\mathrm{SO}_{2}$ concentrations.

\section{Results}

\subsection{Historical changes in sulphur emissions}

The EMEP inventory's twenty-five years of sulphur dioxide emission decreases are presented below in a long-term perspective. Emission data from Mylona $(1996,1997)$ is included prior to 1980 since these emission where comparable with the EMEP inventory for overlapping periods. The historical development of sulphur emissions since 1880 are presented in Fig. 1, based on Mylona $(1996,1997)$ for the period 1880 to 1975 and on the EMEP inventory which is based on official reported emission data, from 1980 and onwards. From the pre-industrial area to the outbreak of the Second World War the European $\mathrm{SO}_{2}$ emissions were in-

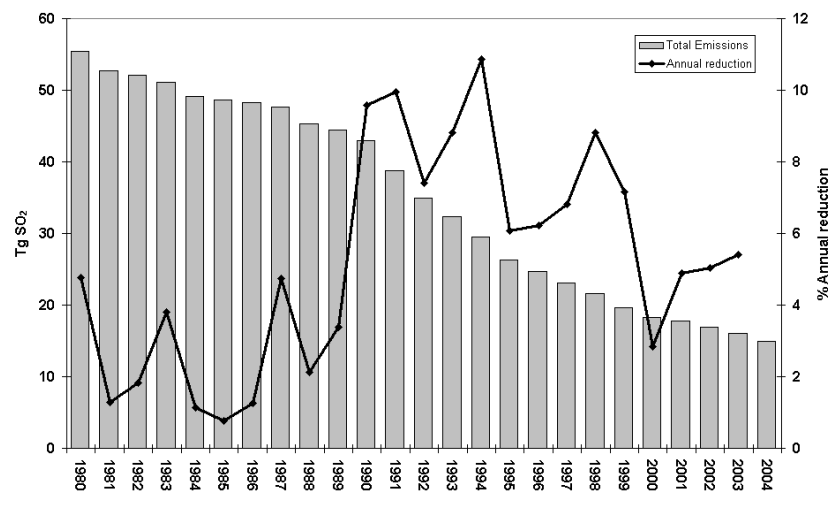

Fig. 2. Total sulphur dioxide emission trend (Unit: $\mathrm{Tg} \mathrm{SO}$ ) and relative annual European emission reduction 1980-2004 (Unit: \%).

creasing slowly but steadily from 5 to $19 \mathrm{Tg} \mathrm{SO}_{2}$ as a result of increase in power generation from solid fuels. The emissions decreased to World War I level during the World War II, but thereafter grew steeply to about $55 \mathrm{Tg} \mathrm{SO}_{2}$ in the late 1970s due also to the availability of liquid fuel to satisfy the increase in energy demand. During the last twentyfive years, European $\mathrm{SO}_{2}$ emissions have decreased rapidly to $15 \mathrm{Tg} \mathrm{SO}$, and have in 2004 reached the same level as 70 years ago. Figure 2 (grey bars) presents a closer look at the last twenty-five years of sulphur reduction in Europe. The reduction since 1980 has been significant $(73 \%)$. The reasons for these considerable reductions are a mixture of the economic situation, implementation of abatement technologies, restructuring of energy sources at national level and increased awareness of the need to reduce sulphur emission through existing international instruments as the Protocols to the LRTAP Convention discussed in some detail below. The emission trends per country as tabulated in Table 1 indicate that while the European $\mathrm{SO}_{2}$ emission trend has been continuously decreasing during the whole period 1980-2004, the emission trends vary considerably between individual countries. In each one of the five-years periods listed in Table 1, there are countries with nearly constant emissions, countries which increase their emissions and others with emission decreases. There are also large variations in the size and location of the emission changes, and these differences are analysed here.

The key sources for $\mathrm{SO}_{2}$ are the sectors Combustion in energy and transformation industries, Non-industrial combustion plants, Combustion in manufacturing industries and Production processes. In Fig. 3 we have plotted the trends in emissions from these sectors from 1990 to 2004. The sector trends are gradually decreasing and flattening out towards 2004. Largest reductions have been obtained from Combustion in energy and transformation industries, followed by Non-industrial combustion plants and Combustion in manufacturing industries. The relative contribution to total $\mathrm{SO}_{2}$ emission from the Combustion in energy and 
transformation industries has increased slightly on behalf of the Non-industrial combustion plants sector. However the key sectors remain the same during the whole period.

Figure 2 displays both absolute and relative annual European emission reductions. Largest relative reductions (black curve) took place in the beginning of the 1990s, with a maximum in 1994-1995 (11\%). Largest absolute reduction (grey bars) is seen between 1990 and 1991 . The annual reduction was smallest in absolute terms between 2000 and 2001, while the relative reductions were only $1 \%$ between multiple years in the 1980s. Based on the annual relative emission reductions, we have identified three emission regimes. The annual sulphur reduction is shown to be below $5 \%$ in 1980 1989 (Low reduction regime) and largest (up to 11\%/year) for 1990-1999 (High reduction regime). The downward emission trend has flattened out from 2000 onwards, and annual reductions for the five year period, 2000-2004 (below $6 \% / y e a r$ ), are almost back to 1980s level (medium-low reduction regime). In the first reduction regime, 1980-1989, the total European reduction was $11 \mathrm{Tg}$ or about $20 \%$. Total reduction in the second ten year period was more than twice as large (23 $\mathrm{Tg}$ or about $54 \%$ ). In the last 5 year period a reduction of only $3 \mathrm{Tg}(17 \%)$ could be observed.

The spatial disaggregation of emissions for the three reduction regimes is presented in the difference maps 19801990, 1990-2000, 2000-2004 in Fig. 4. The picture shows that the countries responsible for the emission reduction during the low reduction regime (Fig. 4a), were mainly Western European, notably Germany, France, Italy, United Kingdom and Spain. Some of the Eastern European countries like the Russian Federation, Poland, Hungary and Czech Republic, did also reduce their emissions, but characteristic for this period is the Eastern European increase of emissions (Fig. 4a). Western European countries were responsible for about $75 \%$ of total European emission reduction in this reduction regime. During the high reduction regime (Fig. 4b), most Eastern European countries decreased their emissions considerably, notably the Russian Federation, Ukraine, Czech Republic, Poland, Bulgaria and Belarus. The Eastern European countries were responsible for about $80 \%$ of total European reductions during the high reduction regime. Only Turkey continued to substantially increase the sulphur emissions in this period. Finally, the most recent reduction regime reflects the unified Europe with about equal, and medium to small reductions in both Western and Eastern Europe as shown in Fig. 4c. Slight increases are seen also in this period in the Former Yugoslavian countries, Greece, the Republic of Moldova, Bulgaria and Finland.

The three reduction regimes defined above are closely connected to the individual countries' political and economical development. In the early 1980s, when the environmental problems connected to acidification were confidently highlighted, no supranational instruments were in place to help policy makers forming long-term strategies to abate emissions. In addition few countries had the economical and

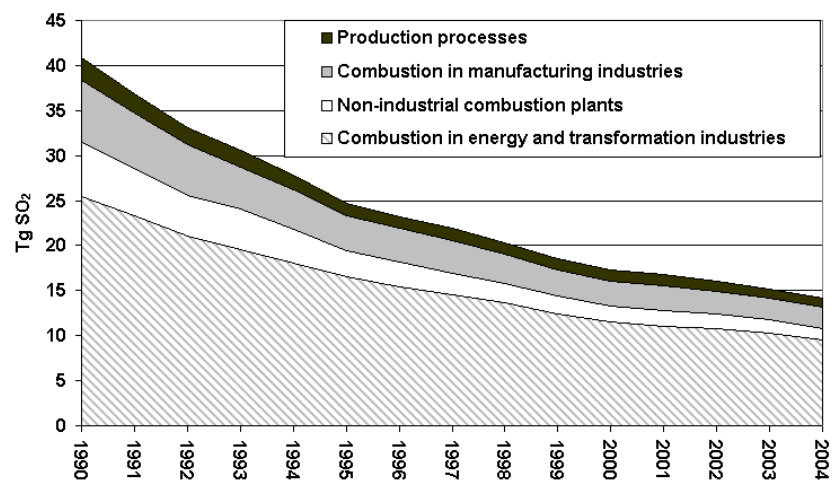

Fig. 3. Sector trends for of sulphur dioxide emission key sources 1990-2004 (Unit: Tg SO 2 ).

technological ability to implement the required measures, and this is reflected in the relatively low European reductions between 1980 and 1999. This situation was dramatically changed in the following ten year period where one sulphur protocol already was in place, the second Protocol was adopted, and work was ongoing in order to prepare for the Gothenburg Protocol. While the Western European countries continued to implement new technologies and fuels in order to meet Protocol targets and reduce the identified environmental problems, the economic recession in Eastern Europe, resulting in a drop in activity level, had a larger overall effect on the emission reductions. From 1995 the activity level in many Eastern European countries stabilized and started slowly to increase. However the emissions kept dropping as measures, in particular Flue Gas Desulphurization (FGD), but also extensive fuel switches from solid/liquid to gaseous fuels were implemented. Lately, the tendency is towards an increase in activity level in both East and West, but the total emissions have not increased yet due to the high penetration of emission control technology.

We have analyzed further our three reduction regimes by comparing trends in fuel consumption with emission trends. It should be noted that, while Parties to the LRTAP Convention are reporting activity data which is linked to the reported emissions on a five-yearly basis from 1990 onwards, fuel consumption data post 1990 consistent with the reported emissions have not been readily available for this study. For the period 1980-1990 we have studied trends in international statistics of solid fuels (UNECE, 1983, 1985b, 1990, 1992). Neither of these sources of fuel consumption data is as complete in terms of temporal resolution and coverage as are the emission data, and a comprehensive analysis by country and sector of the causes for the emission reduction pattern data is not attempted here.

In Eastern Europe, we find that the changes in solid fuel consumption and emissions follow each other closely between 1980 and 1990, while the picture is more dispersed in Western Europe. In Western Europe, emission reductions 

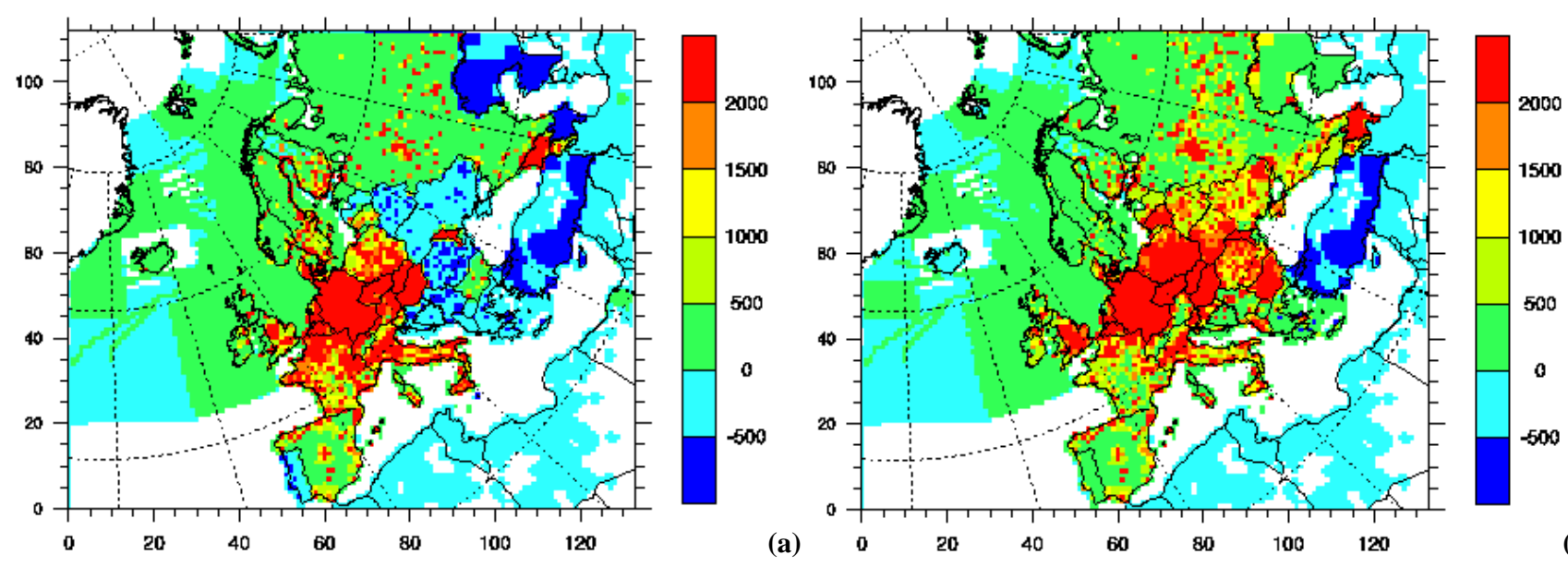

(b)

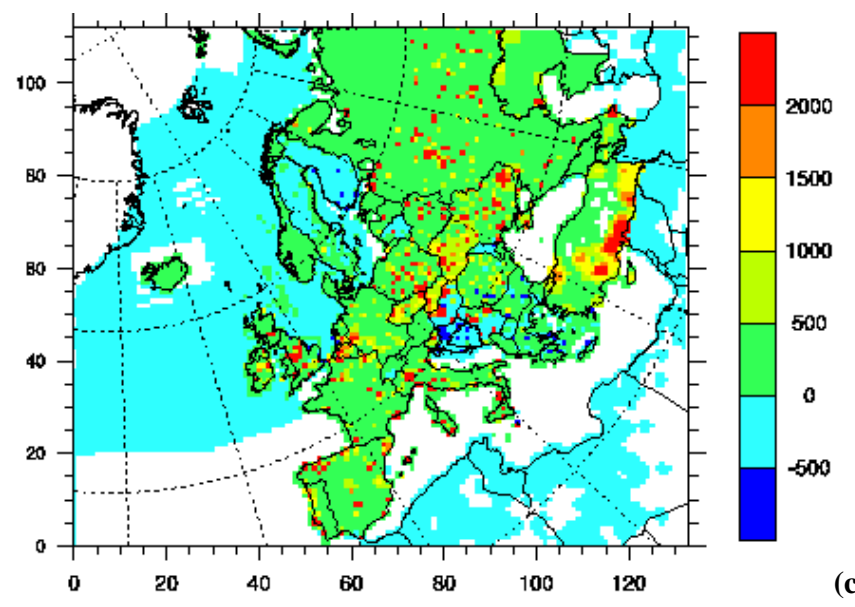

Fig. 4. Difference maps presenting the three European $\mathrm{SO}_{2}$ emission reduction regimes. Reductions between 1980 and 1990 (a: Upper left), reductions between 1990 and 2000 (b: Upper right) and reductions between 2000 and 2004 (c: Bottom). Unit: $\mathrm{Mg} \mathrm{SO}_{2} /$ grid cell. $^{2}$

have been possible also thanks to policy regulations already from the early 1980s, leading to implementation of advanced emission control technologies such as Flue Gas Desulphurization (FGD) (mainly in power generation), together with fuel switch (e.g. from coals with a high sulphur content to gas and or nuclear power) and increased sulphur removal from refined petroleum products, and not because the demand for sulphur producing activities (energy and heat production, industrial and residential combustion) has ceased. Hence, a clear decoupling of $\mathrm{SO}_{2}$ emissions from the trend in activities has been observed already in the first reduction regime in Western Europe.

The period between 1990 and 2000 was dominated by the Eastern Europe socio-political changes and resulting in the transition from a centrally planned economy to a free-market economy. The structural changes were accompanied by a significant drop in industrial production, hence also energy consumption. The resulting decrease in energy production is directly reflected in corresponding emission reductions of sulphur in countries with the largest reductions during this period like Poland and the Czech Republic, as is also pointed out by Mill (2006). Both in Eastern and Western Europe, the reduction in solid fuel consumption were compensated by increased consumption of gas, renewable and nuclear energy particularly in the last part of this period.

The emission abatement strategy in Former East Germany (GDR) and Former West Germany (FRG) is a good example on how policies, implementation of measures and structural changes are closely linked to the emission reduction pattern and how it has been possible to decrease German (GDR and FRG) emissions by $18 \%$ in the 1980s (1980-1989) and by $85 \%$ in the ten year period (1990-1999) following the reunification. In the FRG the reduction of $\mathrm{SO}_{2}$ emissions was forced by the implementation of the Federal Emission Pollution Control Act in year 1974 and by several following Federal Emission control ordinances. These regulations caused a wide spread implementation of highly efficient emission control technologies, as well as a switch from solid fuels like coal and lignite to oil and gas, and increased use of lowsulphur heating oil, and resulted in a gradual drop in FRG sulphur dioxide emissions already from 1974 onwards. On the opposite side, and due to financial restrictions, the economy in the GDR was based to the extent possible on the use of domestic lignite (e.g. in 1989 more than $70 \%$ of the total 
primary energy consumption was based on the combustion of lignite). In the years leading up to 1990 , there was no specific regulation for the use of domestic lignite and - besides a few very small tentative facilities and, started in 1987, one power plant in Berlin - no advanced emission control technologies were in place in the GDR. Hence, the sulphur dioxides emissions in the three largest sectors in GDR, Combustion in energy and transformation industries, Combustion in manufacturing industries and, Non-industrial combustion plants, increased until the end of the 1980s. Since the German reunification in 1990, the reduction of $\mathrm{SO}_{2}$ emission has been dominated by the replacement of old facilities by new ones with the best available technology and regulation for desulphurisation of flue gases in large combustion plants in the eastern part of Germany together with a fuel switch from solid to gaseous and liquid fuels. Since 2001 the national government encouraged the consumption of low-sulphur fuel in the road transportation by a tax discount.

Many countries have already taken necessary steps to substantially decrease their emissions of sulphur. Table 2 shows that by 2004, more than half of the countries have reduced their emissions by $60 \%$ or more of the 1990 values, and one quarter of the countries have reduced emissions by more than $80 \%$. Only two countries report increases in the emission level (Turkey and Greece), which can be explained by growth rates of their economies and the related increasing demand for energy. The absolute reductions obtained between 1990 and 2004 are largest for Germany, the Russian Federation, United Kingdom and Ukraine. Reductions estimated for these countries are larger than the reductions from all the other European countries together and has a pronounced impact on the sulphur deposition pattern in Europe as shown in Fagerli et al. (2006).

It should be noted, however, that there is now an increasing number of countries reporting increased emissions from one year to another to EMEP. The development from the early 1990s when the reductions were largest, and up to present is shown in Fig. 5. The overall trend is clearly increasing, despite some fluctuation. More than $30 \%$ of the European countries reported increased emissions of sulphur from 2002 to 2003. This is more than three times as many as ten years earlier. Some of Europe's largest emitter countries have increased their sulphur emissions from 2000 onwards for the first time since the mid eighties. For most countries, notably the Eastern European countries in which the economy is now recovering, the increase is due to increased public electricity and heat production. The Scandinavian countries, however, report increases in emissions from national shipping. The stabilization of the European emission trend (Figs. 2 and 4), the large reductions already achieved by many countries (Tables 1 and 2) and the growing number of countries reporting annual emission increases (Fig. 5), is a worrying development of the sulphur emission trend in Europe, and it needs to be closely monitored and further assessed.

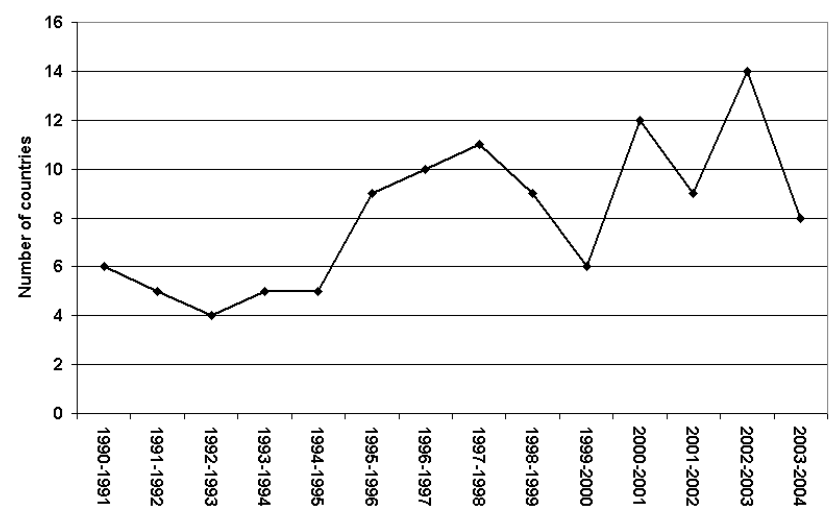

Fig. 5. Number of countries with emission increases from one year to another.

4.2 Comparison of $2004 \mathrm{SO}_{2}$ emission data with targets given by the Gothenburg Protocol

Table 2 shows the level of attainment in 2004 of the Gothenburg Protocol 2010 emissions ceilings. Officially reported emissions for 1990 and 2004 completed as outlined in Sect. 3.1 are listed, together with the 2010 emission ceilings, the percentage reduction from 1990 attained by 2004, and in the last column, the percentage emission reductions between the 1990 base year emissions and the 2010 ceilings as listed for information purposes in the Protocol. The table groups the European countries in three different groups depending on their status relative to the Gothenburg Protocol (UNECE, 2004) and presents the reductions obtained by Parties to the Protocol (i.e. those eighteen European countries which had ratified the Gothenburg Protocol by summer 2006), Signatories and "Other" countries. While Parties and Signatories to the Protocol together with Belarus and Cyprus have 2010 emissions ceilings listed in the Protocol, we have included in Table 2 the 2010 estimates from the RAINS model (Amann et al., 2005b) for remaining countries, including the Russian Federation which only has ceilings for its Pollutant Emissions Management Area (PEMA) listed therein.

On a European level the target for $\mathrm{SO}_{2}$ reduction set by the Gothenburg Protocol has apparently been attained in 2004. As shown at the bottom of Table 2, the total European emissions in 2004 were about $15 \mathrm{Tg} \mathrm{SO}_{2}$, while the sum of 2010 emission targets is $16 \mathrm{Tg} \mathrm{\textrm {SO } _ { 2 }}$. Reductions by individual countries are however still expected to be achieved, as half of the Protocol Parties have to reduce their emissions further to attain the 2010 target established by the Gothenburg Protocol (Table 2). Likewise, both the Signatories and "Other" countries groups have already attained their total 2010 targets of 3.9 and $7.3 \mathrm{Tg} \mathrm{SO}_{2}$ respectively. Based on a comparison between 2004 emissions and Protocol Parties' targets for 2010, the largest near future European reductions should take place in the Western part of Europe, notably in Spain and the United Kingdom since these two countries alone must reduce 
Table 2. Level of attainment in 2004 of the Gothenburg Protocol 2010 emission ceilings. Officially reported emissions for 1990 and 2004 are listed, together with the 2010 emission ceilings, the percentage reduction from 1990 attained by 2004, and the percentage emission reductions between the 1990 base year emissions and the 2010 ceilings as listed for information purposes in the Protocol.

\begin{tabular}{|c|c|c|c|c|c|}
\hline & $\begin{array}{r}1990 \\
\mathrm{Gg} \mathrm{SO}_{2}\end{array}$ & $\begin{array}{r}2004 \\
\mathrm{Gg} \mathrm{SO}_{2}\end{array}$ & $\begin{array}{r}2010 \\
\mathrm{Gg} \mathrm{SO}_{2}\end{array}$ & $\begin{array}{r}2004-1990 \\
\%\end{array}$ & $\begin{array}{r}2010 \\
\%\end{array}$ \\
\hline \multicolumn{6}{|c|}{ Parties to the Gothenburg Protocol } \\
\hline Bulgaria & 2007 & 929 & 856 & -53.7 & -57.0 \\
\hline Czech Republic & 1876 & 227 & 283 & -87.9 & -85.0 \\
\hline Denmark & 176 & 23 & 55 & -86.9 & -70.0 \\
\hline Finland & 259 & 83 & 116 & -68.0 & -55.0 \\
\hline Germany & 5289 & 559 & 550 & -89.4 & -90.0 \\
\hline Latvia & 97 & 4 & 107 & -95.9 & -10.0 \\
\hline Lithuania & 263 & 40 & 145 & -84.8 & -35.0 \\
\hline Luxembourg & 26 & 4 & 4 & -84.6 & -73.0 \\
\hline Netherlands & 189 & 66 & 50 & -65.1 & -75.0 \\
\hline Norway & 53 & 25 & 22 & -52.8 & -58.0 \\
\hline Portugal & 317 & 203 & 170 & -36.0 & -53.0 \\
\hline Romania & 1310 & 685 & 918 & -47.7 & -30.0 \\
\hline Slovakia & 542 & 97 & 110 & -82.1 & -80.0 \\
\hline Slovenia & 198 & 55 & 27 & -72.2 & -86.0 \\
\hline Spain & 2103 & 1360 & 774 & -35.3 & -65.0 \\
\hline Sweden & 117 & 47 & 67 & -59.8 & -44.0 \\
\hline Switzerland & 42 & 17 & 26 & -59.5 & -40.0 \\
\hline United Kingdom & 3699 & 833 & 625 & -77.5 & -83.0 \\
\hline Total Parties & 18563 & 5257 & 4905 & -71.7 & -74.0 \\
\hline \multicolumn{6}{|c|}{ Signatories to the Gothenburg Protocol } \\
\hline Armenia & 86 & 8 & 73 & -90.7 & 0.0 \\
\hline Austria & 74 & 29 & 39 & -60.8 & -57.0 \\
\hline Belgium & 361 & 154 & 106 & -57.3 & -72.0 \\
\hline Croatia & 178 & 85 & 70 & -52.2 & -61.0 \\
\hline France & 1333 & 484 & 400 & -63.7 & -68.0 \\
\hline Greece & 487 & 537 & 546 & 10.3 & 7.0 \\
\hline Hungary & 1011 & 240 & 550 & -76.3 & -46.0 \\
\hline Ireland & 186 & 71 & 42 & -61.8 & -76.0 \\
\hline Italy & 1795 & 496 & 500 & -72.4 & -70.0 \\
\hline Poland & 3278 & 1286 & 1397 & -60.8 & -56.0 \\
\hline Republic of Moldova & 175 & 15 & 135 & -91.4 & -49.0 \\
\hline Total Signatories & 8964 & 3405 & 3858 & -62.0 & -56.0 \\
\hline \multicolumn{6}{|l|}{ Other countries } \\
\hline Albania & 74 & 32 & 30 & -56.8 & -59.5 \\
\hline Azerbaijan & 615 & 130 & 15 & -78.9 & -97.6 \\
\hline Belarus & 888 & 97 & 480 & -89.1 & -25.0 \\
\hline Bosnia and Herzegovina & 484 & 427 & 411 & -11.8 & -15.1 \\
\hline Cyprus & 46 & 45 & 17 & -2.2 & -15.0 \\
\hline Estonia & 274 & 90 & 44 & -67.2 & -83.9 \\
\hline Georgia & 43 & 5 & 9 & -88.4 & -79.1 \\
\hline Iceland & 9 & 9 & 29 & 0.0 & 222.2 \\
\hline Kazakhstan & 651 & 425 & 237 & -34.7 & -63.6 \\
\hline Malta & 29 & 17 & 12 & -41.4 & -58.6 \\
\hline Russian Federation & 6113 & 1858 & 2464 & -69.6 & -59.7 \\
\hline Serbia and Montenegro & 593 & 341 & 277 & -42.5 & -53.3 \\
\hline TFYR of Macedonia & 110 & 87 & 82 & -20.9 & -25.5 \\
\hline Turkey & 1519 & 1792 & 1708 & 18.0 & 12.4 \\
\hline Ukraine & 3921 & 1145 & 1457 & -70.8 & -48.0 \\
\hline Total other countries & 15369 & 6500 & 7272 & -57.7 & -48.0 \\
\hline Grand Total & 42896 & 15162 & 16035 & -64.7 & -61.0 \\
\hline
\end{tabular}


their emissions by $794 \mathrm{Gg} \mathrm{SO}_{2}$. A closer look at those countries with remaining reduction obligation towards 2010 reveals that individual Parties to the Gothenburg Protocol are further away from attaining their emission ceilings than the Signatory countries and countries without commitments towards the Protocol. The total emission reductions required by the Parties $(956 \mathrm{Gg})$ is more than five times higher than the sum of the reductions still required by the Signatories $(176 \mathrm{Gg})$ as indicated in Table 2. "Other" countries will also have to reduce their emissions substantially towards 2010 in order to obtain the targets as listed in Table $2(553 \mathrm{Gg})$, but we must take into account that neither these countries nor the Signatories have firm binding obligations under the Gothenburg Protocol.

\section{Discussion}

\subsection{Evaluation of uncertainties}

In general, the uncertainty of $\mathrm{SO}_{2}$ emissions in the Eastern European countries is larger than for Western European countries because the level of reporting and resources available for in-country quality control is more limited. An additional factor to consider when determining the uncertainty of the emission trends presented in this paper is that the quality of the data varies also in time as some countries only recalculate their time series back to 1990 when improvements in estimation and measurement methodologies become available. In addition, the review and the work on completing the time trends has up to now mostly focussed on post 1990 emissions. Emissions before 1990 might therefore be attributed higher uncertainty than more recent data.

The increased reporting by countries on air pollutant uncertainties in their Informative Inventory Reports (IIR) in combination with uncertainty analysis of LRTAP gases published elsewhere, encouraged a first tentative quantification of the uncertainty in the EMEP $\mathrm{SO}_{2}$ inventory. Uncertainty assessments of greenhouse gases (GHG) for the EU-15 countries were combined (based on Tier 1 estimates from 13 Member States) for the first time in the European Commission National Inventory Report (NIR) 2005 (EC, 2005). The overall uncertainty for all GHG was shown to be 4-8\% measured as $95 \%$ confidence intervals. Lowest uncertainty was found for stationary fossil fuel combustion (1\%). The EMEP inventory is also a compilation of emissions from different sources as pointed out in Sect. 2. The largest part of the EMEP inventory consists of emission data officially reported under the Convention on LRTAP complemented by RAINS emission estimates. We do not have as good coverage of individual countries' uncertainty analysis of air pollutants as is available for the GHG, and are not attempting to provide a complete uncertainty analysis of the EMEP inventory. We present here a compilation of relevant published uncertainty estimates of both officially submitted data (Vestreng et al., 2006b, and references therein) and of RAINS estimates (Schöpp et al., 2005). Uncertainty estimates of air pollutants calculated by Parties rely on the IPCC Good Practice Guidance (IPCC, 2000) adopted for LRTAP gases by Pulles and van Aardenne (2001). Two different methods for uncertainty quantification are recommended therein; a Tier 1 error propagation approach and a Tier 2, stochastic simulation (Monte Carlo) analysis. A Tier 2 approach would make more sense for the quantification of uncertainty in $\mathrm{SO}_{2}$ emissions as significant dependencies and correlations may exist particularly for fossil fuels (IPCC, 2000). However, Van Gijlswijk et al. (2004) show that for the Netherlands there were no substantial differences between Tier 1 and Tier 2 results for $\mathrm{SO}_{2}$. Seven Parties have published their uncertainty estimates. Finland, Norway and United Kingdom have applied Monte Carlo analysis while Denmark, France and Czech Republic rely on the Tier 1 approach. The Netherlands provide both Tier 1 and Tier 2 estimates. The officially reported uncertainty estimates in total $\mathrm{SO}_{2}$ emissions in the Western European countries is rather low and of the order of 3-7\%. Uncertainty in the Czech Republic however was estimated to be about five times larger (Vestreng et al., 2006b). In order to complete the EMEP inventory, modelled emission estimates from the RAINS model (http://www.iiasa.ac.at/rains/) are included, particularly for some of the Eastern European countries. The uncertainty in the modelled $\mathrm{SO}_{2}$ RAINS emission estimates are calculated based on methods specifically developed to analyse the uncertainties in RAINS estimates, considering also the uncertainties in the model parameters themselves. Generally higher uncertainties are found for RAINS estimates than for the officially reported data, and with a typical range of 10 to $15 \%$ (Schöpp et al., 2005). According to Schöpp et al. (2005), data for some Central and Eastern European countries are more uncertain than for the EU-15 countries, but the uncertainty do not exceed $\pm 23 \%$ for any country. We therefore conclude that the uncertainty in the post 1990 emission estimates for individual countries included in the EMEP inventory lies between 3\% and 25\%, implying that the uncertainty in the EMEP inventory as such is lower. Emission data before 1990 might be subject to higher uncertainties as indicated above. Uncertainty in RAINS sector emissions is about twice as large as for the national total due to the more limited potential for error compensation (Schöpp et al., 2005).

In recent years, the lowermost uncertainty level is equally large to the annual European sulphur reduction (Fig. 2). Still, even with their inherit uncertainty, the twenty-five years trends presented here are supported by both models and measurements, and has been accompanied by reported improvements and recovery of adverse effects. Fagerli et al. (2006) shows that there has been a major reduction in the risk damage of acidification to ecosystems all over Europe from 1990-2004. While 40\% of Parties to the Gothenburg Protocol had their ecosystems at risk in 1990, the unprotected area has decreased to $20 \%$ in 2004 (Fagerli et al., 2006). 


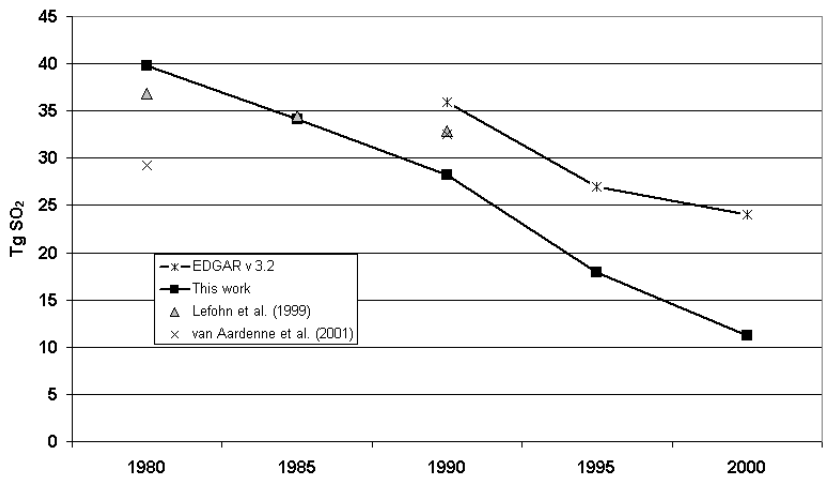

Fig. 6. Comparison of $\mathrm{SO}_{2}$ inventories for Europe 1980-2000 (OECD Europe and Eastern Europe, excluding former USSR countries, Turkey and Cyprus) (Unit: $\mathrm{Tg} \mathrm{SO}_{2}$ ).

Skjelkvåle et al. (2005) report also widespread improvement in surface water chemistry since 1990. Last but not least, the increased effort by the Parties to the LRTAP Convention to develop good in-country QA/QC systems, followed by enhanced transparency in emission estimation methods and uncertainties documented in the IIRs, together with the ongoing emission review process, allows for an improved confidence in the officially reported emissions used for air quality and health impact modelling.

5.2 Comparison with other anthropogenic $\mathrm{SO}_{2}$ emission estimates

The share of European emissions (EMEP inventory) to global anthropogenic emissions has been reduced from $40 \%$ in 1980 to $18 \%$ in 2000 . This implies that the European contribution to global anthropogenic sulphur emissions has more than halved over the last two decades. The global estimates referred to here are those compiled and estimated by Stern et al. (2006). It should be noted that while estimates of global sulphur emission estimates compare well in level and trend up to 1950 , relatively larger differences may occur particularly after 1980 (e.g. Lefohn et al., 1999; Olivier and Berdowski, 2001; Smith et al., 2001). A comparison between the most recent global total sulphur inventories by Smith et al. (2004) and Stern (2006) between 1980 and 2000 shows however that they compare surprisingly well taken into account the differences in estimation methodology applied in most areas. The global total estimates of sulphur emission differ by less than $5 \%$ between 1980 and 1992 while the differences increase to $12 \%\left(6.5 \mathrm{Tg} \mathrm{SO}_{2}\right)$ in 2000 , Stern (2006) estimating lower emissions than Smith et al. (2001). Both Smith et al. (2004) and Stern (2006) include the EMEP inventory for Europe and are hence excluded from the following comparison with this inventory.

Our comparison is therefore focussed to the three inventories of Lefohn et al. (1999), van Aardenne et al. (2001) and EDGAR version 3.2 inventory (Olivier and Berdowski,
2001) as presented in Fig. 6. The EMEP inventory is the only of these inventories covering the whole time span of interest (1980-2004), so the comparison is carried out there where data from the other inventories is available. For the period 1980 to 1990 the annually resolved inventory from Lefohn et al. (1999) and the ten yearly resolved data per region from van Aardenne et al. (2001) are included in the comparison. Between 1990 and 2000, the five yearly resolved EDGAR inventory (Olivier and Berdowski, 2001) were included. The two latter inventories are related as they are both based on the same constant $1990 \mathrm{SO}_{2}$ emissions factors provided by J. Berdowski as personal communication (Aardenne et al., 2001) in addition to international statistics. The emission factors provided by Berdowski are country-specific and based on the sulphur contents of different fuels and metal ores and country-specific sulphur recovery by smelters, refineries and FGD in power generation (J. Olivier, personal communication, 2007). Lefohn et al. (1999) base their calculation on national and international statistics for the extraction and production of sulphur bearing fuels and metals, sulphur content in those fuels and varying degree of Flue Gas Desulphurization (FGD) control. In contrast, the EMEP inventory is based on country specific technology dependent emission factors and both national and international activity statistics. In order to make sure that we compare emissions from identical areas, we decided to exclude emissions from the territory of the Former USSR, Turkey and Cyprus, and concentrate the comparison on the areas "OECD Europe" and "Eastern Europe" as defined in EDGAR.

A year by year comparison between the EMEP inventory and Lefohn et al. (1999) inventories (not shown in Fig. 6) between 1980 and 1990 shows that these two inventories compare well in level and trend up to 1984, Lefohn et al. (1999) estimating around 5\% lower emissions. Thereafter Lefohn et al. (1999) estimate an increase in emissions between 1984 and 1986 and coincide with the EMEP inventory in 1985. Lefohn et al. (1999) emissions are relatively constant between 1986 and 1989 and decrease with the same gradient as the EMEP inventory between 1989 and 1990. Both Lefohn et al. (1999) and the EMEP inventory show an overall emission decrease between 1980 and 1990, but the Lefohn et al. (1999) emission reduction is rather small compared to EMEP (Fig. 6). The difference between the inventories is three times larger in 1990 than in 1980, and might be attributed to difference in applied emission control, a factor which becomes increasingly important with time for the accuracy of emission estimates.

Van Aardenne et al. (2001) indicate an increasing trend in sulphur emissions between 1980 and 1990, opposing the trend in both Lefohn et al. (1999) and the EMEP inventory (Fig. 6). The reason for this is an increase in emissions in Eastern Europe. Since the emission factors are kept constant, this increase should be due mainly to increases in the consumption of solid fuels, as discussed in Sect. 4. The main difference between the inventories seems to be that the 
1990 emission factors applied to estimate the van Aardenne et al. (2001) 1980 emissions were low compared to those applied in the EMEP and Lefohn et al. (1999) inventory.

We see from Fig. 6 that for the year 1990 all the inventories included in the comparison have relatively similar emissions estimates. The difference between the EDGAR and the EMEP inventories is $28 \%$, while the van Aardenne et al. (2001) and Lefohn et al. (1999) total European estimates for 1990 coincide. The comparison made between the van Aardenne et al. (2001) and Lefohn et al. (1999) global inventories in the paper by van Aardenne et al. (2001) shows that also the 1990 global total estimates are the same. Possible explanations for this similarity in emission estimates at both global and regional scale are not discussed in van Aardenne et al. (2001), and it is not possible for us either to conclude if this is a mere coincidence or an indication of a better accuracy in these estimates. Best comparability was anticipated to be found between the EDGAR and the van Aardenne (2001) emission estimate for 1990 since the emission factors used in these inventories are the same. It seems however that e.g. difference in the activity data and or the more refined sector split in EDGAR give higher 1990 emissions for Europe than van Aardenne et al. (2001). Between 1990 and 2000 both the EDGAR and the EMEP emissions for Europe are strongly reduced, but the trends are flattening out towards year 2000 . The EDGAR emission estimates are highest throughout the whole ten year period. The difference between the inventories increases with time, and particularly the last five years. Attention should be paid to the fact that by the year 2000 the difference in $\mathrm{SO}_{2}$ emission estimates between the two inventories is as large as the EMEP total European emissions. The increasing difference between the inventories may be attributed to the lack of technology dependent emission factors in the EDGAR inventory, and the comparison with our work tentatively quantifies the importance of this dependence towards year 2000 .

\section{Conclusions}

The emissions estimates presented here are compiled and validated under the EMEP programme as part of the work under the Convention on Long-range Transboundary Air Pollution (LRTAP). They conclude that European $\mathrm{SO}_{2}$ emissions have dropped by $73 \%$ between 1980 and 2004. Reductions of sulphur emissions have been largest in the Combustion in energy and transformation industries sector, and reductions have been obtained both due to policy regulation followed by implementation of measures, and to economic recession. It is shown that the sulphur emission reductions were largest in the 1990s. Three distinct emission regimes have been identified. During the first period from 1980 to 1989 emission reductions were generally low (20\%), and largest in Western Europe. The highest emission reductions were reported in Eastern European countries during the second period, 1990-
1999, characterised by high emission reductions (54\%). The unification of Europe has lead to a more equally spread reduction pattern, with low-medium reductions all over Europe, and a total reduction of $17 \%$ in the first half of the 2000s.

Our analysis of the reasons behind the emission changes in Europe shows that the policy development plays an important part in order to reduce emissions. While the Eastern European changes in fuel consumption is directly reflected in the sulphur emissions during the first reduction regime, the Western European emissions are already decoupled from the fuel consumption thanks also to policy regulations already from the early 1980s, leading to implementation of advanced emission control technologies and changes in the fuel mix notably from coal to oil and gas. During the second reduction regime, the economic recession in Eastern Europe and accompanying drop in activity level, had a factor 1.5 larger effect than policy measures taken in the western part on the overall European sulphur reduction. Recent increases in fuel consumption in the recovering economies in Eastern Europe and also in Western Europe, is mainly from fuels which do not contain appreciable amount of sulphur. In addition, penetration of control technology all over Europe is reflected in a small but continuous decrease in European sulphur emissions.

The amount of officially reported emissions to EMEP which can be confidently used in trend studies vary both in time and space and this is reflected in the uncertainty of the EMEP inventory. Eastern European emission inventories and emission estimates prior to 1990 are consider to have associated the highest uncertainties. Further, we tentatively conclude that the uncertainty in the total $\mathrm{SO}_{2}$ emissions is between $3 \%$ and $25 \%$ for individual countries and years comprising the EMEP inventory, implying that the uncertainty in the EMEP inventory as such is lower. The EMEP emission data is subject to national QA/QC documented in Informative Inventory Reports, external annual inventory reviews, and has in addition been validated by models and measurements that support the reported trends (Lövblad et al., 2004; Fagerli et al., 2003). The sulphur emission reductions have been accompanied by a widespread improvement in surface water acidity and exceedances of critical loads ${ }^{1}$ (WGE, 2004; Skjelkvåle et al., 2005; Fagerli et al., 2006). The reduced sulphate concentrations over Europe have lead to a reduction in the cooling effect of sulphate aerosols. Local responses to a radiative effect are yet uncertain (Hansen et al., 2005). However, with such a strong reduction in the $\mathrm{SO}_{2}$ emissions it is likely that this has contributed to a warming of Europe.

According to the EMEP estimates, the European contribution to the global anthropogenic sulphur emissions has more

\footnotetext{
${ }^{1}$ The basic idea of the critical load is to balance the deposition rate to an ecosystem with its long-term capability to buffer the input or to remove it without harmful effects inside or outside the system (Hettelingh et al., 2001; UBA, 2004)
} 
than halved over the last two decades. The EMEP inventory has been compared with other independent estimates provided by Lefohn et al. (1999), van Aardenne et al. (2001) and EDGAR version 3.2 inventory (Olivier and Berdowski, 2001). The downward trend over Europe is steeper in the EMEP inventory than in all the other inventories. This is probably due to the fact that the EMEP inventory uses more detailed country specific emission factors and includes changes in technology mixes. From 1990 onwards the importance of capturing the changes in technologies by applying emission factors reflecting national circumstances becomes more evident in the comparison. The EMEP inventory shows an increasingly larger emission reduction between 1990 and 2000 than the EDGAR inventory which is based on constant 1990 emission factors. It should also be noted that by the year 2000 the EDGAR estimate of total European emissions is more than twice as large as the EMEP estimate.

After the stabilization of the European $\mathrm{SO}_{2}$ emissions since 2000, when many countries have already achieved emissions reductions of 60-80\% with respect to $1990 \mathrm{lev}$ els, an increasing number of countries have started to report increases in national emissions. This is a worrying development that needs to be further assessed, especially as it contradicts the expectations from the target setting of exiting international instruments to reduce sulphur emissions. From the perspective of the Gothenburg Protocol, further reductions should be expected, particularly in Western Europe. The Protocol target seems to be reached on a European level already by 2004, but half of the Parties have not yet fulfilled the requirements therein. In the longer term, larger reductions from Eastern Europe could be expected as several Eastern European countries have as of yet not reached an abatement level reflecting the state of the art in control technologies available. Emissions from international shipping, is not considered in this paper but clearly also influence the air quality and climate (e.g. Derwent et al., 2005; Marmer and Langemann, 2005). The trends in the ships emissions contrast the land based trends by an estimated increase of about $2.5 \%$ annually on cargo and 3.9\% on passenger vessels in European waters (Cofala et al, 2007; Vestreng et al., 2006). Moreover, the $\mathrm{SO}_{2}$ emissions from shipping are projected to increase by $42 \%$ from 2000 to 2020 in the current legislation baseline scenario (Cofala et al., 2007). Depending on ambition level, the emission from ships might stabilize or even decrease by as much as $70 \%$ in the case where maximum technological feasible reductions are considered. Regional differences in trends are expected, as the sulphur emissions in the Baltic Sea and the North Sea are now regulated by the MARPOL Convention Annex VI (MARPOL, 1978) which entered into force in 2005.

Acknowledgements. We would like to thank the Parties to the Convention on LRTAP for collecting and submitting emission data to EMEP and for their active participation in the review of emission data. Financial support from the EMEP Trust Fund is gratefully acknowledged. Many thank also to Z. Klimont and J. Cofala at the International Institute for Applied Systems Analysis (IIASA) for providing the RAINS data. This work was also supported by the European Commission's Fifth Framework program by the CARBOSOL Project (contract No. EVK2-2001-00067) and the European Topic Centre for Air Quality and Climate Change (ETC-ACC). Many thanks also due to U. Döring and M. Strogies, Umweltbundesamt, Germany, for discussions on the German abatement strategies and to B. L. Skjelkvåle, Norwegian Institute for Water Research, for her inspiring comments to the draft manuscript. We would also like to thank the two reviewers, J. G. J. Olivier, Netherlands Environment Assessment Agency (MNP) and J. Theloke, Institute of Energy Economics and the Rational Use of Energy (IER), University in Stuttgart, for their constructive and helpful comments. The EMEP work is a free contribution to the ACCENT network of Excellence.

Edited by: F. J. Dentener

\section{References}

Akselsson, C., Ardö, J., and Sverdrup, H.: Critical loads of acidity for forest soil and relationship to forest decline in the northern Czech Republic, Environ. Monit. Assess., 98, 363-379, 2004.

Amann, M., Bertok, I., Cabala, R., Cofala, J., Heyes, C., Gyarfas, F., Klimont, Z., Schöpp, W., and Wagener, F.: CAFÉ Scenario Analysis Report Nr. 5, Exploratory CAFÉ scenarios for further improvements of European air quality, Laxenburg, Austria, pp. 66, 2005a.

Amann, M., Bertok, I., Cofala, J., Gyarfas, F., Heyes, C., Klimont, Z., Schöpp, W., and Winiwarter, W.: CAFÉ Scenario Analysis Report Nr. 1, Baseline Scenarios for the Clean Air for Europe (CAFÉ) Programme, Final Report. Baseline Scenarios for the Clean Air for Europe (CAFÉ) Programme, Final Report, Contract No B4-3040/2002/340248/MAR/C1, Laxenburg, Austria, pp. 76, 2005b.

Berglen, T. F., Myhre, G., Isaksen, I. S. A., Vestreng, V., and Smith, S.: Sulphate trends in Europe: Are we able to model the recent observed decrease?, Tellus, doi:j.1600-0889.2007.00289.x, available from http://www.blackwell-synergy.com/doi/pdf/10. 1111/j.1600-0889.2007.00289.x, 2007.

Boucher, O. and Pham, M.: History of sulphate aerosol radiative forcings, Geophys. Res. Lett., 29(9), 22-25, doi:10.1029/2001GL014048, 2002.

Breivik, K., Vestreng, V., Rozovskaya, O., and Pacyna, J. M.: Atmospheric emissions of some POPs in Europe: a discussion of existing inventories and data needs, Environ. Sci. Policy, 9, 663674, doi:10.1016/j.envsci.2006.09.001, 2006.

Cofala, J., Amann, M., Heyes, C., Wagner, F., Klimont, Z., Posch, M., Schöpp, W., Tarassón, L., Jonson, J. E., Whall, C., and Stavrakaki, A.: Analysis of Policy Measures to reduce Ships Emissions in the Context of the Revision of the National Emissions Ceilings Directive, Final Report, European Commission, DG Environment, Unit ENV/C1, Contract No 070501/2005/419589/MAR/C1, available from http://ec.europa. eu/environment/air/transport.htm\#3, 2007.

Dentener, F., Kinne, S., Bond, T., Boucher, O., Cofala, J., Generoso, S., Ginoux, P., Gong, S., Hoelzemann, J., Ito, A., Marelli, L., Penner, J. E., Putaud, J.-P., Textor, C., Schulz, M., van der Werf, G. R., and Wilson, J.: Emissions of primary aerosol and 
precursor gases in the years 2000 and 1750 prescibed data-sets for AeroCom, Atmos. Chem. Phys., 6, 4321-4344, 2006,

http://www.atmos-chem-phys.net/6/4321/2006/.

Derwent, R. G., Stevenson, D. S., Doherty, R. M., Collins, W. J., Sanderson, M. G., Johnson, C., Cofala, J., Mechler, R., Amann, M., and Dentener, F.: The contribution from shipping emissions to air quality and acid deposition in Europe, Ambio, 34(1), 5459, 2005.

EC: Directive 2001/81/EC, OJ L 309, 22-30, 27 November, 2001.

Eliassen, A. and Saltbones, J.: Modelling of long-range transport of sulphur over Europe: A two-year model run and some model experiments, Atmos. Environ., 17, 1457-1473, 1983.

EU: The Treaty of Accession 2003 of the Czech Republic, Estonia, Cyprus, Latvia, Lithuania, Hungary, Malta, Poland, Slovakia and Slovenia. AA2003/ACT/AnnexII/en 2072, available from http: //ec.europa.eu/, 2003.

Fagerli, H., Simpson D., and Aas, W.: Chapter 1: Model performance for sulphur and nitrogen compounds for the period 1980 to 2000, in: EMEP report 1/2003, Part II. Transboundary acidification, eutrophication and ground level ozone in Europe, ISSN 0806-4520, 2003.

Fagerli, H., Spranger, T., and Posch, M.: Chapter 3: Acidification and eutrophication - progress towards the Gothenburg protocol target year (2010), in: EMEP Report 1/2006, Transboundary acidification, eutrophication and ground level ozone in Europe from 1990 to 2004 in support for the review of the Gothenburg Protocol, ISSN 1504-6109 (print), 2006.

Fowler, D., Sutton, M. A., Flechard, C., Cape, J. N., Storeton-West, R., Coyle, M., and Smith, R. I.: The control of $\mathrm{SO}_{2}$ dry deposition on to natural surfaces by $\mathrm{NH} 3$ and its effect on regional deposition, Water Air Soil Poll., 1, 39-48, 2001.

Grennfelt, P. and Hov, Ø.: Regional air pollution at a turning point, Ambio, 34(1), 2-10, 2005.

Gunn, J. M. and Sandøy, S.: Introduction to the Ambio special issue on biological recovery from acidification: Northern lakes recovery study, Ambio, 32(3), 162-164, 2003.

Hansen, J., Sato, M., Ruedy, R., Nazarenko, L., Lacis, A., et al.: Efficacy of climate forcings, J. Geophys. Res., 110(D18), D18104, doi:10.1029/2005JD005776, 2005.

Haywood, J. and Boucher, O.: Estimates of the direct and indirect radiative forcing due to tropospheric aerosols: A review, Rev. Geophys., 38(4), 513-543, 2000.

Henriksen, A., Lien, L., Rosseland, B. O., Traaen, T. S., and Sevaldrud, I. S.: Lake acidification in Norway - present and predicted fish status, Ambio, 18, 314-321, 1989.

Hettelingh, J.-P., Posh, M., and De Smet, P. A. M.: Multi-Effect critical loads used in multi-pollutant reduction agreements in Europe, Water Air Soil Poll., 130, 1133-1138, 2001.

IPCC: Penman, J., Kruger, D., Galbally, I., Hiraishi, T., Nyenzi, B., Emmanul, L., Buendia, S., Hoppaus, R., Martinsen, T., Meijer, J., Miwa, K., and Tanabe, K. (Eds.): Good Practice Guidance and Uncertainty Management in National Greenhouse Gas Inventories, IPCC National Greenhouse Gas Inventories Programme, Published for the IPCC by the Institute for Global Environmental Strategies, Japan, ISBN 4-88788-000-6, available from http://www.ipcc-nggip.iges.or.jp/public/gp/english/, 2000.

Langner, J., Bergström, R., and Foltescu, V.: Impact of climate change on surface ozone and deposition of sulphur and nitrogen in Europe, Atmos. Environ., 39(6), 1129-1141, 2005.
Lefohn, A. S., Husar, J. D., and Husar, R. B.: Estimating historical anthropogenic global sulphur emission patterns for the period 1850-1990, Atmos. Environ., 33, 3435-3444, 1999.

Lohmann, U. and Feichter, J.: Global indirect aerosol effects: a review, Atmos. Chem. Phys., 5, 715-737, 2005, http://www.atmos-chem-phys.net/5/715/2005/.

Lövblad, G., Tarrasón, L., Tørseth, K., and Dutchak, S. (Eds.): EMEP Assessment Report Part I, European Perspective, ISBN 82-7144-032-2, available from http://www.emep.int, Oslo, 2004.

Marmer, E. and Langmann, B.: Impact of ship emissions on the Mediterranean summertime pollution and climate: A regional model study, Atmos. Environ., 39(2005), 4659-4669, doi:101016/j.atmosenv.2005.04.014, 2005.

MARPOL: International Convention for the Prevention from Ships, 1973, as modified by the Protocol of 1978 relating thereto, http: //www.imo.org/HOME.html, 1978.

Mayerhofer, P., de Vries, B., den Elzen, M., van Vuuren, D., Onigkeit, J., Posch, M., and Guardans, R.: Long-term, consistent scenarios of emissions, deposition, and climate change in Europe, Environ. Sci. Policy, 5(4), 273-305, 2002.

Menz, F. C. and Seip, H. M.: Acid rain in Europe and the United States: an update, Environ. Sci. Policy, 7(4), 253-265, doi:10.1016/j.envsci.2004.05.005, 2004.

Mill, W.: Temporal and spatial development of critical loads exceedance of acidity to Polish forest ecosystems in view of economic transformations and national environmental policy, Environ. Sci. Policy, 9(6), 563-567, doi:10.1016/j.envsci.2006.05.002, 2006.

Mylona, S.: Sulphur dioxide emissions in Europe 1880-1991, Tellus, 48B, 662-689, ISSN 0280-6509, 1996.

Mylona, S.: Corrigendum to Sulphur dioxide emissions in Europe 1880-1991, Tellus, 49B, 447-448, ISSN 0280-6509, 1997.

Myhre G., Stordal, F., Berglen, T. F., Sundet, J., and Isaksen, I. S. A.: Uncertainties in the Radiative Forcing Due to Sulfate Aerosols, J. Atmos. Sci., 61(5), 485-498, 2004.

Nellemann, C. and Goul Thomsen, M.: Long-term changes in forest growth: Potential effects of nitrogen deposition and acidification, Water Air Soil Poll., 128, 197-205, 2001.

OECD: The OECE programme on Long Range Transport of Air Pollutants. Measurements and Findings, Report 35.192, Paris, 1977.

Olivier, J. G. J. and Berdowski, J. J. M.: Global emissions sources and sinks, in: The climate system, edited by: Berdowski, J. J. M., Guicherit, R., and Heij, B. J., A. A. Balkema Publishers/Swets \& Zeirlinger Publishers, Lisse, The Netherlands, ISBN 905809255 0, 33-78, 2001.

Pulles, T., and van Aardenne, J. (Eds.): Good Practice Guidance for CLRTAP Emission Inventories, Draft chapter for the UNECE CORINAIR Guidebook on Emission Inventories, available from http://reports.eea.eu.int/EMEPCORINAIR4/en/BGPG.pdf, 2001.

Ramanathan, V., Crutzen, P. J., Kiehl, J. K., and Rosenfeld, D.: Aerosols, Climate, and the Hydrological Cycle, Science, 294, 2119-2124, 2001.

Roelofs, G.-J., Lelieveld, J., and Ganzeveld, L.: Simulation of global sulfate distribution and the influence on effective cloud drop radii with a coupled photochemistry sulfur cycle model, Tellus, 50B, 224-242, 1998.

Rohde, H., Grennfelt, P., Wisniewski, J., Ågren, C., Bengtsson, G., 
Johansson, K., Kauppi, P., Kucera, V., Rasmussen, L., Rosseland, B., Schotte, L., and Selldén, G.: Acid Reign '95 - Conference summary statement, Water Air Soil Poll., 85, 1-14, 1995.

Sanderson, M. G., Collins, W. J., Johnson, C. E., and Derwent, R. G.: Present and future acid deposition to ecosystems: The effect of climate change, Atmos. Environ., 40(7), 1275-1283, 2006.

Schulz, M., Textor, C., Kinne, S., Balkanski, Y., Bauer, S., Berntsen, T., Berglen, T. F., Boucher, O., Dentener, F., Guibert, S., Isaksen, I. S. A., Iversen, T., Koch, D., Kirkevåg, A., Liu, X., Montanaro, V., Myhre, G., Penner, J. E., Pitari, G., Reddy, S., Seland, $\varnothing$, Stier, P., and Takemura, T.: Radiative forcing by aerosols as derived from the AeroCom present-day and pre-industrial simulations, Atmos. Chem. Phys., 6, 5225-5246, 2006, http://www.atmos-chem-phys.net/6/5225/2006/.

Schöpp, W., Posch, M., Mylona, S., and Johansson, M.: Long-term development of acid deposition (1880-2030) in sensitive freshwater regions in Europe, Hydrol. Earth Syst. Sci., 7, 436-446, 2003 , http://www.hydrol-earth-syst-sci.net/7/436/2003/.

Schöpp, W., Klimont, Z., Suutari, R., and Cofala, J.: Uncertainty analysis of emission estimates in the RAINS integrated assessment model, Environ. Sci. Policy, 8, 601-613, doi:10.1016/j.envsci.2005.06.008, 2005.

Simpson, D., Winiwarter, W., Börjesson, G., Cinderby, S., Ferreiro, A., Guenther, A., Hewitt, C. N., Janson, R., Khalil, M. A. K., Owen, S., Pierce, T. E., Puxbaum, H., Shearer, M., Skiba, U., Steinbrecher, R., Tarrasón, L., and Öquist, M. G. : Inventorying emissions from nature in Europe, J. Geophys. Res., 104, 81138152, 1999.

Skjelkvåle, B. L., Evans, C., Larssen, T., Hindar, A., and Raddum, G. G.: Recovery from acidification in European surface waters: A view to the future, Ambio, 32(3), 170-175, 2003.

Skjelkvåle, B. L., Stoddard, J. L., Jeffries, D. S., Tørseth, K., Høgåsen, T., Bowman, J., Mannio, J., Monteith, D. T., Mosello, R., Rognora, M., Rzychon, D., Vesely, J., Wieting, J., Wilander, A., and Worsztynowicz, A.: Regional scale evidence for improvements in surface water chemistry 1990-2001, Environ. Poll., 137, 165-176, 2005.

Sliggers, J. and Kakebeeke, W. (Eds.): Clearing the Air, 25 years of the Convention on Long-Range Transboundary Air Pollution, United Nations, New York and Geneva, ECE/EB.AIR/84, ISBN 92-1-116910-0, 2004.

Smith, S. J., Pitcher, H., and Wigley, T. M. L.: Global and regional anthropogenic sulphur dioxide emissions, Global Planet. Change, 29, 99-229, 2001.

Smith, S. J., Andres, R., Conception, E., and Lurz, J.: Historical sulphur Dioxide Emissions 1850-2000: Methods and Results, PNNL Research Report prepared for the U.S. Department of Energy under the Contract DE-AC06-76RL01830, Joint Global Change Research Institute, 8400 Baltimore Avenue, College Park, Maryland 20740, Pacific Northwest National Laboratory, PNNL-14537, 2004.

Stern, D. I.: Global sulphur emissions from 1850 to 2000, Chemosphere, 58, 163-175, doi:10.1016/j.chemosphere.2004.08.022, 2005.

Stern, D. I.: Reversal of the trend in global anthropogenic sulphur emissions, Global Environ. Change, 6, 207-220, doi:10.1016/j.gloenvacha.2006.01.001, 2006.

Stoddard, J. L., Jeffries, D. S., Lukewille, A., Clair, T. A., Dillon,
P. J., Driscoll, C. T., Forsius, M., Johannessen, M., Kahl, J. S., Kellogg, J. H., Kemp, A., Mannio, J., Monteith, D. T., Murdoch, P. S., Patrick, S., Rebsdorf, A., Skjelkvåle, B. L., Stainton, M. P., Traaen, T., van Dam, H., Webster, K. E., Wieting, J., and Wilander, A.: Regional trends in aquatic recovery from acidification in North America and Europe, Nature, 401(6753), 575-578, 1999.

Tarrasón, L., Klein, H., Thunis, P., Vestreng, V., and White L.: Emission distributions used for source-receptor calculations and CAFÉ scenario analysis, Chapter 3 in EMEP Report 1/2004, Transboundary acidification, eutrophication and ground level ozone in Europe, EMEP Status Report, ISSN 0806-4520, available from http://www.emep.int, 2004.

UBA (Ed.): Manual on methodologies and criteria for modelling and mapping critical loads and levels, and air pollution effects, risks and trends, German Federal Environmental Agency, Berlin, Germany, continuous updates available from http://www. icpmapping.org, 2004.

UNECE: Energy statistics yearbook, United Nations, New York, USA, 1983.

UNECE: Energy statistics yearbook, United Nations, New York, USA, 1985 b.

UNECE: Energy statistics yearbook, United Nations, New York, USA, 1990.

UNECE: Energy statistics yearbook, United Nations, New York, USA, 1992.

UNECE: Emission Reporting Guidelines, Air Pollution Studies no. 15, available from www.unece.org/env/eb/ Air_Pollutionwithcover_15_ENG.pdf, 2003.

UNECE: Handbook for the 1979 Convention on Long-Range Transboundary Air Pollution and its Protocols, United Nations, New York and Geneva, ECE/EB.AIR.5, ISBN 92-1-116895-32004, http://www.unece.org/env/lrtap/ (including amendment of December 2005), 2004.

UNECE: Emission inventories and projections, progress report by the Co-Chairs of the Task Force, prepared in consultation with the secretariat, Annex III: Draft methods and procedures for the technical review of air pollutant emission inventories reported under the Convention and its protocols, EB.AIR/GE.1/2005/7, available from http://www.unece.org/env/eb/welcome.23.html, 2005.

Van Aardenne, J. A., Dentener, F. J., Olivier, J. G. J., Klein Goldewijk, C. G. M., and Lelieveld, J.: A $1^{\circ} \times 1^{\circ}$ resolution dataset of historical anthropogenic trace gas emissions for the period 18901990, Global Biogeochem. Cy., 15(4), 909-928, 2001.

Van Gijlswijk, R., Coenen, P., Pulles, T., and Van der Sluijs, J. P.: Uncertainty assessment of NOx, $\mathrm{SO} 2$ and $\mathrm{NH} 3$ emissions in the Netherlands, TNO report R2004/100, TNO, Apeldoorn, available from http://www.rivm.nl/bibliotheek/digitaaldepot/ TNOreportRa2004.pdf, 2004.

Van Loon, M., Wind, P., and Tarrasón, L.: Meteorological variability in source allocation: Transboundary contributions across Europe, in: Transboundary Acidification, Eutrophication and Ground Level Ozone in Europe, EMEP Status Report 1/2005, pp 89-107, Norwegian Meteorological Institute, Oslo, Norway, available from http://www.emep.int, 2005.

Vestreng, V.: Review and Revision, Emission data reported to CLRTAP, MSC-W Status Report 2003, Note 1/2003, ISSN 08042446, available from http://www.emep.int, 2003.

Vestreng, V., Breivik, K., Adams, M., Wagner, A., Goodwin, J., Ro- 
zovskaya, O., and Pacyna, J. M.: Inventory Review 2005, Emission data reported to LRTAP and NEC Directive, Initial review of HMs and POPs, EMEP/MSC-W Technical Report 1/2005, ISSN 0804-2446, available from http://www.emep.int, 2005.

Vestreng, V., Rigler, E., Adams, M., Kindbom, K., Pacyna, J. M., Denier van der Gon, H., Reis, S., and Travnikov, O.: Inventory review 2006, Emission data reported to LRTAP and NEC Directive, Stage 1, 2 and 3 review and Evaluation of inventories of HM and POPs, EMEP/MSC-W Technical Report 1/2006 ISSN 1504-6179, available from http://www.emep.int, 2006a.

Vestreng, V., Tarrasón, L., Rigler, E., Klein, H., and Benedictow, A. C.: Emissions: progress towards the emission ceilings in the Gothenburg Protocol, Chapter 2 in EMEP Status Report 1/2006, ISSN 1504-6109, available from http://www.emep.int, 2006b.

WHO: Air quality guidelines for Europe, second edition, Copenhagen, WHO regional office for Europe, WHO regional publications, European series No 91, available from http://www.euro. who.int/air/activities/20050223_4, 2000.
WHO: Health aspects of air pollution with particulate matter, ozone and nitrogen dioxide, Report on a WHO working group, Copenhagen, WHO Regional Office for Europe (document EUR/03/5042688), available from http://www.euro.who. int/document/e79097.pdf, 2003.

WHO: WHO air quality guidelines global update 2005, Report on a working group meeting, Bonn, Germany, 18-20 October 2005, WHOLIS number E87950, 2005.

WHO: Health risks of particulate matter from long-range transboundary air pollution, joint WHO/Convention Task Force on the Health Aspects of Air Pollution, WHO Regional Office for Europe, European Centre for Environment and Health, Bonn Office, WHOLIS number E88189, 2006.

WGE: Working Group on Effects 2004, Review and assessment of air pollution effects and their recorded trends, Working Group on Effects, Convention on Long-range Transboundary Air Pollution, National Environment Research Council, United Kingdom, xiv+99 pp. 66, ISBN 187039377 5, 2004.

Yakovlev, V. A.: Toxicity and accumulation of Al in the acid water of small lakes and watercourses in Finnish Lapland, Water Resources, 28(4), 413-419, 2001. 